\title{
1 Increasing temperature threatens an already endangered coastal dune plant
}

3 Contact information of authors: Aldo Compagnoni ${ }^{1,2}$, Eleanor Pardini ${ }^{3}$, \& Tiffany M. Knight ${ }^{1,2,4}$

4

$5 \quad{ }^{1}$ Institute of Biology, Martin Luther University Halle-Wittenberg, Am Kirchtor 1,06108, Halle

6 (Saale), Germany, aldo.compagnoni@gmail.com

$7 \quad{ }^{2}$ German Centre for Integrative Biodiversity Research (iDiv) Halle-Jena-Leipzig, Deutscher Platz

8 5e, 04103, Leipzig, Germany

$9 \quad{ }^{3}$ Environmental Studies Program, Washington University in St. Louis, 1 Brookings Drive, Box

10 1165, St. Louis, MO 63130, USA

$11{ }^{4}$ Department of Community Ecology, Helmholtz Centre for Environmental Research - UFZ,

12 Theodor-Lieser-Straße 4, 06120, Halle (Saale), Germany

13

14 Person to whom correspondence should be sent: Aldo Compagnoni, German Centre for

15 Integrative Biodiversity Research (iDiv) Halle-Jena-Leipzig, Deutscher Platz 5e, 04103, Leipzig,

16 Germany, aldo.compagnoni@gmail.com 


\section{ABSTRACT}

19 Climate change has the potential to reduce the abundance and distribution of species and threaten

20 global biodiversity, but it is typically not listed as a threat in classifying species conservation

21 status. This likely occurs because demonstrating climate change as a threat requires data-

22 intensive demographic information. Moreover, the threat from climate change is often studied in

23 specific biomes, such as polar or arid ones. Other biomes, such as coastal ones, have received

24 little attention, despite being currently exposed to substantial climate change effects. We forecast

25 the effect of climate change on the demography and population size of a federally endangered

26 coastal dune plant (Lupinus tidestromii). We use data from a 14-year demographic study across

27 seven extant populations of this endangered plant. Using model selection, we found that survival

28 and fertility measures responded negatively to temperature anomalies. We then produced

29 forecasts based on stochastic individual based population models that account for uncertainty in

30 demographic outcomes. Despite large uncertainties, we predict that all populations will decline if

31 temperatures increase by $1^{\circ}$ Celsius. Considering the total number of individuals across all seven

32 populations, the most likely outcome is a population decline of $90 \%$. Moreover, we predict

33 extinction is certain for one of our seven populations. These results demonstrate that climate

34 change will profoundly decrease the current and future population growth rates of this plant, and

35 its chance of persistence. Thus, our study provides the first evidence that climate change is an

36 extinction threat for a plant species classified as endangered under the USA Endangered Species

37 Act. 
bioRxiv preprint doi: https://doi.org/10.1101/2020.08.02.233288; this version posted October 27, 2020. The copyright holder for this preprint (which was not certified by peer review) is the author/funder, who has granted bioRxiv a license to display the preprint in perpetuity. It is made available under aCC-BY-NC-ND 4.0 International license.

39 Keywords: climate change, forecast, integral projection model, individual based model, life

40 table response experiment, population dynamics.

41 


\section{INTRODUCTION}

44 Year to year variation in weather influences demographic processes such as survival, growth and

45 reproduction, and ultimately population persistence (Sæther et al. 2000). For many natural

46 populations, climate change will increase the frequency of weather conditions outside the

47 physiological tolerances of individuals, and is thus expected to reduce the number, size and

48 distribution of populations (IPCC 2014). As a result, conservation planning (Akçakaya et al.,

49 2014) and projections of biodiversity change (Pereira et al. 2010) will benefit from

50 understanding how climate change will threaten population viability.

51 Researchers typically use species distribution models (SDMs) to assess the effects of climate

52 change on species (Elith and Leathwick 2009). However, species distributions might include

53 declining populations of the species because of a currently unsuitable climate (Schurr et al.

54 2012). Subsequently, while SDMs describe current ranges well, their prediction of future ranges

55 are highly uncertain (Keenan et al. 2011). Hence, forecasting the effect of climate change on

56 species persistence should be more reliable using process-based models that require long-term

57 demographic data across the entire life cycle of the organism (Ehrlén and Morris 2015, Paniw et

58 al. 2019). Despite this, our knowledge on how climate drives demography is relatively limited,

59 with most studies coming from animals in cold and arid biomes. For example, changing

60 temperature has been linked to reductions in population growth rates of alpine plants (Doak and

61 Morris 2010, Campbell 2019, Iler et al. 2019) and polar animals (Jenouvrier et al. 2009, Hunter

62 et al. 2010). Changing precipitation has been linked to changes in population growth rates of

63 organisms in arid environments (Tews and Jeltsch 2004, Jonzén et al. 2010). However, the effect 
64 of climate change in other biomes, regardless of their extent or importance to humans, has

65 received less attention.

66 Coastal ecosystems are a biome for which the extinction threat from climate change has received

67 little attention. This occurs despite the importance of species conservation for human well-being

68 (Díaz et al. 2019), and despite the importance of coastal ecosystems and their susceptibility to

69 climate change. Coastal ecosystems occupy a small portion of terrestrial surface, but are home to

$7041 \%$ of the human population (Martínez et al. 2007) and to a large portion of the earth's

71 economy; for example, 31\% of the USA gross domestic product in 1985 (Luger 1991). Coastal

72 biomes protect inland ecosystems during storms by attenuating or resisting wave action (Barbier

73 2015). Current and future climate change in coastal ecosystems is altering precipitation patterns,

74 increasing the frequency of high temperature extremes (USGCRP 2018), and causing habitat loss

75 and salt water inundation (Feagin et al. 2005). To date, demographic research on coastal dune

76 plants has focused on understanding the effects of plant-animal interactions and succession (e.g.

77 Maron 1998, Dangremond et al. 2010a, Pisanu et al. 2012, Pardini et al. 2015, Cogoni et al.

78 2019). Thus, it is timely to consider the effects of climate on the demography of coastal species.

79 Understanding the effect of climatic drivers on future population size requires quantifying how

80 the link between climate and demography translates into population dynamics. Studies

81 establishing such link are the foundation to prioritize conservation efforts. For example, the polar

82 bear was listed as a threatened species under the endangered species act thanks to demographic

83 studies (USFWS 2015). Demographic analysis linked warming-induced reductions in sea ice

84 extent to reductions in survival and breeding probabilities, and increased risk of extinction

85 (Hunter et al. 2010). As a result of this work, the US Fish and Wildlife Service indicated curbing

86 Arctic warming as the most important conservation action for this species (USFWS 2015). Such 
87 demographic studies are most useful when carried out across multiple populations, in order to

88 account for the substantial variation in populations sizes and vital rates (Glenn et al. 2010).

89 Here, we examine the effect of changing climate on the vital rates and population growth of a

90 perennial coastal dune plant. We first link the effect of climate on separate vital rates, and we use

91 an integral projection model to estimate their contribution to population growth rate. Then, we

92 use an individual based model to forecast the effect of projected climate change on future

93 population numbers in the next 30 years. These numerical simulations account for the effect of

94 initial population numbers, year to year stochastic weather, and demographic stochasticity. We

95 parameterize these models using a 14-year data set that comprehensively sampled 7 of the 15

96 known remaining populations of this species. The populations we included range from the

97 smallest to the largest known (17 and 180000 individuals, respectively). Our focal species,

98 Lupinus tidestromii, is listed as endangered under the USA endangered species act, but to date,

99 climate change is not considered a threat to this or any plant species.

100

101 MATERIALS AND METHODS

102

103 Study Species and Site

104 Lupinus tidestromii (Fabaceae) is a perennial, herbaceous plant that is endemic to coastal dunes

105 in northern California, where it is found in 15 extant populations. These populations are located

106 in Sonoma, Monterey, and Marin counties, seven of these are contained within Point Reyes

107 National Seashore (Figure 1). In this protected area, the population located at Abbotts Lagoon

108 contains more than $50 \%$ of the remaining individuals of the entire species (USFWS 2009). $L$.

109 tidestromii was listed as federally endangered in 1992 and among its primary threats are habitat 
110 loss, trampling by visitors and cattle, hybridization, direct competition with invasive plants, and

111 elevated levels of seed predation in the presence of the invasive grass Ammophila arenaria

112 (USFWS 2009, Dangremond et al. 2010b). Our study was conducted at Point Reyes National

113 Seashore (latitude: 33.1120, longitude: -122.9579). This site has a Mediterranean climate, with

114 wet winters and dry summers (Evens 2008).

115 L. tidestromii is a herbaceous perennial plant that typically lives three years. It produces prostrate

116 stems, and small, upright inflorescences with a whorl of flowers that produce leguminous fruits

117 (Baldwin et al. 2012). Seeds are dispersed locally by explosive dehiscence (USFWS 1998).

118 Seeds have a tough coat that likely allows survival for many years in the seed bank. However,

119 seeds that do not germinate within the first two years become buried by sand. We assume these

120 seeds do not contribute to the short-term population dynamics, but that they can contribute to

121 population growth after disturbance (Pardini et al. 2015). Flowers experience occasional insect

122 herbivory, and fruits and seeds experience pre- and post-dispersal seed predation by the native

123 Peromyscus maniculatus (deer mouse). We have never observed pre-dispersal insect seed

124 predation.

125

126 Monitoring

127 We began demographic censuses in 2005 at three sites (AL, ATT, NB) in 2005, and expanded

128 monitoring at an additional four sites (Pop9, DR, BR, and BS) in 2008 (Fig. 1). Populations NB,

129 BS, and DR are small enough that we monitored every individual plant in the population each

130 year. In AL and BR, and ATT and Pop9 starting in 2013 and 2015, we stratified sampling,

131 censusing plants located in clusters across the extent of the population. We haphazardly chose

132 plants across a range of sizes and microhabitats. Annually, we also tagged at least 50 new 
133 seedlings across each site. We know total population counts for ATT, Pop9, NB, BS, and DR for

134 every year. We inferred population counts for NB, BS, and DR, and we counted the total number

135 of individuals in the populations after starting stratified sampling in ATT and Pop9.

\section{Vital rate data}

138 To quantify the vital rates, in 2005, we started censusing tagged plants in June when fruits on

139 most plants were dehiscing. These censuses quantified the transition rates from one year $(t)$ to the

140 next $(t+1)$. To track individuals, we attached numbered aluminum tags to the basal stem of

141 plants, or staked these tags near plants. We relocated plants each year using a GPS and a metal

142 detector. For each plant, every year we recorded size, survival, flowering status, and number of

143 flowering inflorescences. We quantified size approximating the surface area covered by each

144 individual (Appendix S1).

145 For reproductive plants, we recorded the total number of inflorescences and of those that were

146 aborted, consumed, or intact. Flowers on inflorescences can abort or produce fruits; fruits can be

147 clipped by mice or remain intact, dehisce and disperse seeds. We used the fate of inflorescences

148 to calculate abortion, and consumption (pre-dispersal seed predation), for each population and

149 year.

150 To calculate abortion, we summed the number of aborted inflorescences and divided by the sum

151 of the total number of observed inflorescences. To calculate consumption, we summed the

152 number of clipped inflorescences, and divided by the sum of the number of not aborted

153 inflorescences. The resulting abortion and consumption are population-level means, because we

154 performed the sums to calculate these metrics across all the plants in each population. We do not 
155 have observations on abortion and consumption for all populations and all years. We have

156 abortion rates for all populations in 2010 and 2011, and from 2013 to 2017 (Appendix S2: Fig.

157 S2) and consumption rates for all years except 2012 (Appendix S2: Fig. S3). In years and

158 locations for which we did not have an abortion or consumption rate, we used the population-

159 specific mean taken across censuses.

160 We assumed the number of fruits per inflorescence, and the number of seeds per fruit are

161 constant across years and populations. We calculated fruits per inflorescence using data from

162 2011, averaging the number of fruits across all inflorescences for each plant, and then averaging

163 across plants to produce a population-level value. We quantified the average number of seeds per

164 fruit by counting seeds in 213 randomly collected fruits from multiple years and populations:

165 AL: 2005 (23), 2008 (3), 2009 (15), 2010 (39); ATT: 2011 (33); BR: 2010 (23); DR: 2010 (10),

1662011 (17); NB: 2010 (16) Pop9: 2010 (15).

167 We estimated germination rates through a field germination trial and calculated a recruitment

168 adjustment factor to account for post-dispersal seed predation, and for other sources of

169 unaccounted seed or seedling mortality. We installed caged seed baskets in 2008 at the AL

170 population, and recording the proportion of seedlings that germinated in $2009\left(g_{1}\right), 2010\left(g_{2}\right)$,

171 and $2011\left(g_{3}\right)$ (Pardini et al. 2015). Here $g_{2}$, and $g_{3}$ represent emergence out of seed bank stages.

172 We then calculated a recruitment adjustment factor to account for post-dispersal seed predation

173 and for other sources of unaccounted seed or seedling mortality. To account for these other

174 sources of seed and seedling loss, we used our known population counts to estimate a

175 recruitment adjustment factor, $\delta_{p}$, for each $p$ population (Appendix S3). We modified

176 germination rates $g_{1}, g_{2}$, and $g_{3}$ employed in the IPM using $\delta_{p}$ as $g_{t}\left(1-\delta_{p}\right)$. We could only

177 calculate $\delta_{p}$ for the five populations with known population counts (see "monitoring"). For 
178 population BR and ATT, we applied the mean of $\delta_{p}$ from BS and DR, and from ATT and Pop9,

179 respectively the closest populations to BR and ATT.

181 Modeling of size-dependent vital rates and climate effects

182 We modeled four vital rates as size dependent processes for each year and site: survival, growth,

183 the probability of flowering, and the number of inflorescences. We modeled these vital rates

184 based on generalized mixed linear models. We fit models in R using the lme4 package (Bates et

185 al. 2015), and we performed a preliminary model selection based on Akaike Information

186 Criterion (Burnham and Anderson 2002). In this preliminary model selection, we compared

187 models predicting vital rates using linear, quadratic, and cubic predictors. Our baseline model

188 structure included a random intercept and slope (the effect of size on the vital rate) for both years

189 and populations:

$$
\operatorname{link}\left(\widehat{\psi_{\iota t p}}\right)=\gamma_{t}+\gamma_{p}+\beta_{t} \log \left(Z_{i}\right)+\beta_{p} \log \left(Z_{i}\right)
$$

191 where $\hat{\psi}$ is the mean prediction of the vital rate model for individual $i$, in year $t$, at population $p$,

$192 Z$ is the size of individual $i$, the $\gamma$ coefficients are normally distributed random intercepts, the $\beta$

193 coefficients are normally distributed random slopes of log size, and link is the link function for

194 the vital rate being modelled. The link function depended on the type of response variable. The

195 models on survival (S) and flowering (F) used a logit link, because the response variable is

196 Bernoulli distributed:

$$
F_{i t p} \sim \operatorname{Bernoulli}\left(\widehat{F}_{i t p}\right)
$$


199 The number of inflorescences $(\mathrm{R})$ used a log link, because this response variable follows a

200 Poisson distribution:

$$
R_{i t p} \sim \operatorname{Poisson}\left(\widehat{R}_{i t p}\right)
$$

202 Finally, the growth model used an identity link: that is, it did not use a link function:

$$
G_{i t p} \sim \operatorname{Normal}\left(\widehat{G}_{i t p}, \sigma\right)
$$

204 The best survival model was a cubic function of $\log ($ size $)$, so that:

$$
\operatorname{logit}\left(\widehat{S_{\text {ttp }}}\right)=\gamma_{t}+\gamma_{p}+\beta_{t} \log \left(Z_{i}\right)+\beta_{p} \log \left(Z_{i}\right)+\beta_{2} \log \left(Z_{i}\right)^{2}+\beta_{3} \log \left(Z_{i}\right)^{3}
$$

For the remaining three vital rates, the best model included only a linear predictor (Eq. 1). We selected which climatic predictor, if any, affected vital rates by performing a leave-one-year-out cross-validation. We selected whether climatic drivers increased the predictive power of our

209 linear models (Eq. 1 and 6) and, if so, what climatic drivers improved predictive power the most.

210 The models in this cross-validation simply added the climatic predictor to the vital rate models

211 (Eq. 1-6). We considered four climatic predictors: temperature, precipitation, Oceanic Niño

212 Index (ONI) (CPC n.d.), and the standardized precipitation evapotranspiration index (SPEI,

213 Vicente-Serrano et al. 2009). We obtained temperature and precipitation data starting in 1990

214 from the PRISM dataset (Daly et al. 1994), the ONI data from the internet site of the Climate

215 Prediction Center of the National Oceanic and Atmospheric Administration (CPC n.d.), and we

216 derived the SPEI using our precipitation and temperature data using the R package SPEI

217 (Beguería and Vicente-Serrano 2017). We calculated the yearly climate anomalies for each one

218 of these four drivers. We computed anomalies using the mean and standard deviation observed

219 between 1990 and 2018. Here, we define "year" as the time elapsing between demographic

220 censuses: from June to May of the following year. 
221 For each of the four climatic drivers, we used two yearly anomalies: one referred to the year

222 leading up to the current census $(t)$, and one to the year leading up to the preceding census $(t-1)$.

223 For example, for year $2012(\mathrm{t}=2012)$ we considered the climate anomaly observed between June

2242011 and May 2012, and between June 2010 and May 2011 to predict the flowering probability

225 and number of inflorescences observed in June 2012, and to predict the survival and growth

226 occurred from June 2012 to June 2013. We thus tested for a lag in the effect of climatic drivers

227 on plant vital rates (see also Teller et al. 2016; Tenhumberg et al. 2018).

228 We measured model performance summing the negative log-likelihood of each out-of-sample

229 prediction, with the best model having the lowest score. We used negative log-likelihood as it

230 provides a scoring rule across all of our generalized linear models that yields maximum values

231 when the predicted values coincide with the true ones (Gneiting and Raftery 2007). We fit the

232 final models using the best climatic predictor (if any).

\section{Population projections}

235 We quantified the effect of a changing climate on the population dynamics of L. tidestromii

236 looking at its projected long-term population growth rates and population sizes. We projected

237 long-term population growth rates using an integral projection model (IPM, Ellner et al. 2016),

238 and future population sizes using an individual based model (IBM). We used IBMs to add

239 demographic stochasticity, which is a key component to predict population sizes, particularly for

240 smaller populations (Lande 1993, Caswell 2001).

241 We used an IPM because it is a computationally inexpensive way to perform stochastic

242 population projections of species whose dynamics depend on a continuous state variable: in this 
243 case, the size of individuals. We constructed the IPM using the parameters of the vital rates

244 models described above. We designed most of these IPM parameters to change based on year

245 and population. The IPM projects the number of z-sized L. tidestromii individuals, represented

246 by vector $n(z)$, to the number of z-sized individuals next year, represented by vector $n\left(z^{\prime}\right)$. This

247 population is also composed of seeds that germinate one year after the projection interval,

248 represented by scalar $B_{1}$, and two years after, represented by scalar $B_{2}$. The dynamics of the 249 population are given by

250

$$
B_{1, t+1}=(1-a)(1-c) \iota \kappa g_{2}(1-\delta) \int_{L}^{U} p_{b}\left(z ; \beta_{c}\right) b\left(z ; \beta_{c}\right) n(z, t) d z+B_{2, t}
$$

We show a schematic representation that links these equations to the life cycle of $L$. tidestromii individuals, $z$, three of which depend on temperature anomaly, $\beta_{c}$, while the remaining

257 demographic rates are size- and climate-independent. Three vital rates are size- and climate-

258 dependent: $p_{b}\left(z ; \beta_{c}\right)$ is the size- and climate-dependent probability of flowering, $b\left(z ; \beta_{c}\right)$ is the

259 size- and climate-dependent production of inflorescences, $\mathrm{s}\left(z ; \beta_{c}\right)$ is the size- and climate-

260 dependent probability of survival, and $G\left(z^{\prime}, z\right)$ is size-dependent growth. The size- and climate-

261 independent vital rates mostly refer to the transition from the number of inflorescences to the

262 number of establishing seedlings. In particular, $a$ is the population- and year-specific abortion

263 rate, $c$ is the population- and year-specific consumption rate (or pre-dispersal predation), $l$ is the 264 average number of fruits produced per inflorescence, $\kappa$ is the average number of seeds produced 
265 per fruit, $\delta$ is the recruitment adjustment factor (Appendix S3), and $g$ values refer to germination

266 rates. $g_{0}$ is the fraction of seeds that germinate before the end of the first transition, $g_{1}$ is the

267 fraction of seeds that germinate before the end of the second transition, and $g_{2}$ is the fraction of

268 seeds that germinate before the end of the third transition. Finally, $\eta\left(z^{\prime}\right)$ is the size distribution of

269 seedlings emerging by the end of the transition.

270 We used this IPM to compute the effect of climate on $\lambda_{\mathrm{s}}$, the long-term stochastic population

271 growth rate, and to elucidate this effect through perturbation analyses. We computed the

272 stochastic population growth rate, $\lambda_{s}$, by projecting the population numbers of each one of our

273 seven population 50000 times. We started with a population of only one individual, discarding

274 the first 1000 projections to allow populations to reach a stable size distribution. These stochastic

275 simulations kept a constant average annual temperature, and randomly varied the year-specific

276 conditions (parameters $\gamma_{t}$ and $\beta_{t}$ in Eq. 1 and 6). We calculated $\lambda_{s}$ as $\log \left(\lambda_{s}\right)=E\left[\log \left(\frac{N_{t+1}}{N_{t}}\right)\right]$,

277 where E calculates the mean, and $\mathrm{N}$ is the total population size at the end $(t+1)$ and at the

278 beginning $(t)$ of a transition. We repeated these projections across the whole range of observed

279 climate anomalies we observed during our study period. Our best climatic predictor was always

280 temperature. Therefore, we calculated $\lambda_{\mathrm{s}}$ from an average annual temperature of about $11^{\circ}$

281 Celsius to an average annual temperature of $13^{\circ}$.

282 To understand the effects of temperature on $\lambda_{\mathrm{s}}$, we performed retrospective and prospective

283 perturbation analyses (Caswell 2000). In particular, we performed a Life Table Response

284 Experiment (LTRE, a retrospective analysis), and further analyzed its results through an

285 elasticity analysis (a prospective analysis). The LTRE quantified the difference in $\lambda_{\mathrm{s}}$ observed

286 when only one of the vital rates responded to deviations from the mean temperature. For

287 example, we calculated $\lambda_{\mathrm{s}}$ for an IPM where only survival experienced the full range of 
temperature anomalies. In these simulations, all other vital rates experienced average climate

289 (about $12^{\circ}$ Celsius). We then calculated the contribution of each vital rate to the effect of climate.

290 This contribution is the difference between the $\lambda_{\mathrm{s}}$ computed by these stochastic simulations, and

291 the $\lambda_{\mathrm{s}}$ where all vital rates experienced a $12^{\circ}$ Celsius climate.

292 To better interpret these LTRE results, we calculated vital rate elasticities for the lower level

293 parameters of the IPM (Eq. 7-9; Fig. 2). The LTRE results depend on the sensitivity to the

294 parameter $\beta_{c}$ in the vital rate models (Eq. 7-9). However, we provided the elasticity analysis of

295 all lower level parameters, to place these results in the context of the entire life cycle. We

296 calculated these elasticities using the asymptotic population growth rate $(\lambda)$ as a proxy for $\lambda_{s}$.

\section{Forecast}

299 We forecasted population numbers through an IBM that incorporates probabilistic events of the

300 life cycle by projecting the dynamics of each individual. Given our life cycle (Fig. 2), these

301 probabilistic events were: survival, growth, probability of flowering, production of

302 inflorescences, the abortion of inflorescences, the consumption of inflorescences, and the

303 germination of seeds. We simulated each of these processes using the appropriate statistical

304 distributions (Appendix S4).

305 We used this IBM to produce a forecast of population sizes in the next 30 years that included

306 uncertainty arising from process and demographic stochasticity. We projected each population

307 for 30 time steps, and we replicated each run 1000 times. Each run included a different sequence 308 of years, and a different realization of each vital rate process (Appendix S4, Eq. 1-7). We started 309 each simulation with the number of individuals observed in June 2018, assuming the stable stage 
310 distribution suggested by the population-specific IPM model. We ran two simulations: one

311 assuming the current mean climate (average annual temperature of $12^{\circ}$ Celsius), and one

312 assuming the largest weather anomaly we observed during our 2005-2018 study period (which

313 was a year with an average temperature of $13^{\circ}$ Celsius). A mean annual temperature of $13^{\circ}$

314 Celsius is a conservative forecast, because projections suggest that in 2055 , temperature will be

315 on average 2.1 Celsius higher than the 1990-2018 mean (Vose et al. 2017). We used the 1000

316 simulations for each population and climate scenario to calculate $95 \%$ confidence intervals of

317 population abundances during the 30 -year projections.

\section{RESULTS}

\section{Vital rates and population growth}

322 Plant vital rates and consumption varied across our seven populations and 14-year study period

323 (Appendix S2: Fig. S2-S7). As a result, asymptotic population growth rates $(\lambda)$ was variable

324 across space and time, and our two largest populations (AL, ATT) and the transitions years

325 2011-2012 and 2016-2017 were associated with relatively high values of $\lambda$ (Appendix S2: Fig.

326 S8). There was a remarkable population crash between 2014 and 2015 (Appendix S2: Fig. S8).

\section{Observed and future climate variation}

328 Across our 14-year study period, we observe variation in weather on par with that across longer

329 time periods (Appendix S5: Fig. S9), but not within the range of weather projected with climate

330 change by the middle of the century (Wang et al. 2016, n.d.). For example, mean annual

331 temperature was $11.5^{\circ} \mathrm{C}$ across the study period, $12^{\circ} \mathrm{C}$ from $1990-2018$. This temperature is 
332 projected to increase to about $14^{\circ} \mathrm{C}$ (range: $13.8-14.6^{\circ} \mathrm{C}$ ) by 2055 according to the

333 Representative Concentration Pathway of $4.5 \mathrm{~W} / \mathrm{m}^{2}$ (Wang et al. 2016, n.d., Vose et al. 2017).

334 The range of annual temperatures observed from $1990-2018$ was $11-13^{\circ} \mathrm{C}$, and thus we only

335 consider conservative scenarios of a $1^{\circ} \mathrm{C}$ increase in temperature.

\section{Vital rates and population responses to climate}

337 Growth did not respond to climate, but the remaining three size-dependent vital rates correlated

338 negatively with average annual temperature (Fig. 3, Appendix S2: Fig. S4, Fig. S6-7). There is a

339 sharp decline in population growth rate with increasing mean annual temperature (Fig. 4A).

340 While the slope of the relationship between population growth rate and annual temperature is

341 similar for all populations, these vary in their mean vital rates (i.e., their intercepts and slopes,

342 Appendix S2: Fig. S4-7). If the temperatures remained at the 1990-2018 mean $\left(12^{\circ} \mathrm{C}\right)$, three of

343 the four smallest populations would be expected to decline. At these temperatures, the remaining

344 four populations, including the three largest, are projected to grow. On the other hand, in a

345 scenario where mean annual temperature increases by $1^{\circ} \mathrm{C}$, all populations are projected to

346 decline (Fig. 4A).

347 The LTRE analyses indicate that the decline in population growth rate with increasing

348 temperature is primarily due to the effects of temperature on plant survival (Fig. 4B). Two

349 factors explain the high contribution of plant survival on the change in population growth rate.

350 First, population growth rate is very sensitive to changes in survival (Appendix S6: Fig. S10),

351 and second, survival responds dramatically to increasing temperature (Fig. 4A).

\section{Forecast}


353 Population trajectories indicate that if temperature remained at its 1990-2018 average, this

354 endangered plant species would double its population number in the next 30 years. However,

355 with a $1^{\circ} \mathrm{C}$ increase in temperature, there would be a $90 \%$ average reduction in individuals (Fig.

356 5). This scenario is conservative, as more dramatic increases in temperature are projected for this

357 region in the next 30 years (Wang et al. 2016, n.d., Vose et al. 2017).

\section{DISCUSSION}

361 Our results demonstrate that climate change is having profound negative effects on the current

362 and future population growth rates of L. tidestromii. Within the next 30 years, climate change

363 will result in high probabilities of extinction for four out of the seven populations we analyzed.

364 These high extinction probabilities add to the substantial decrease in total population size. As our

365 analysis considers 7 of the 15 extant populations of the species, including the largest population,

366 it is clear that climate change will substantially deteriorate the conservation status of $L$.

367 tidestromii.

368 We hypothesize that our results could reflect a general pattern among species evolved in coastal

369 dune habitats experiencing low variation in annual temperatures. Low variation in climatic

370 variables, both temporally and spatially (e.g. across topographic gradients), should decrease the

371 ability of species to respond to climatic changes. This expectation is justified because climatic

372 variation in time and space selects for high genetic variability and high phenotypic plasticity

373 (Nadeau et al. 2017). Dune plants of the pacific coast such as L. tidestromii experience low

374 variability in annual temperature, and do not occur across large topographic gradients. The 
375 standard deviation in annual temperatures at our study populations is only $0.43^{\circ}$ Celsius, which

376 is below the $5^{\text {th }}$ percentile of those found across the conterminous United States. Low variation

377 in annual temperatures should be common among Western temperate coasts as a result of

378 Westerly currents. Moreover, dune plants occur only at sea level, and therefore they are not

379 adapted to relatively small topographic gradients. Given these considerations, it might be fruitful

380 to carry out comparative tests on the climatic sensitivity of taxa adapted to dune habitats of mid-

381 latitude Western coasts.

382 Alternatively, our results for L. tidestromii could reflect an isolated case, because climate change

383 can threaten species in any biome as long as their physiological tolerances are exceeded. For

384 example, L. tidestromii could be vulnerable because it thrives only within a narrow range of

385 temperatures (Jenouvrier, 2013). One of the reasons for a narrow temperature niche is that the

386 geographic distribution of rare species like L. tidestromii could be much smaller than its potential

387 (Svenning and Skov 2004). If L. tidestromii did not fill its potential range, its populations could

388 fall, by sheer luck, at sites whose average climate is close to the upper limits of its thermal

389 physiological tolerance. An additional hypothesis for such high climate sensitivity is that the

390 phylogeny of L. tidestromii might make this species prone to physiological stress from heat. The

391 productivity of legume crops is very sensitive to heat stress (Liu et al. 2019), a trait which might

392 be shared with wild legumes.

393 Our results show three advantages of demographic approaches compared to species distribution

394 modeling. First the temporally explicit projections of our demographic models provide highly

395 relevant information to conservation planning and prioritization (Fig. 5). Second, demographic

396 analysis holds mechanistic insights. In our case, we found that the population growth rate of $L$.

397 tidestromii responds to climate mainly through survival. Hence, management actions that 
increase average individual survival might ameliorate the risks imposed by climate change.

399 Finally, it would be hard or impossible to construct an SDM for L. tidestromii. This species

400 occurs in just three locations which differ in average temperature by just 0.12 degrees Celsius.

401 Moreover, the minimum number of sites needed to build an SDM free of statistical artifacts is

402 above 10 (Proosdij et al. 2016). Hence, long-term population or demographic data might be a

403 preferable way to devise climate change forecasts for species that have a geographically

404 restricted range. Some authors suggest that establishing a link between demographic rates and

405 climatic drivers might require 20 to 25 years of data (Teller et al. 2016, Tenhumberg et al. 2018).

406 Instead, our results show that such long data collection might not be needed when a study period

407 spans a large range of climate anomalies (Appendix S5: Fig. S9).

408 To our knowledge, the evidence we present here is the first example suggesting that climate

409 change should be included as a threat in the status for a species listed under the Endangered

410 Species Act. To date, climate change has been considered in listing actions for four animal

411 species occurring in arctic, alpine, or arid biomes. These animals are the polar bear, the

412 American pika, the American wolverine, and the Gunnison sage-grouse (Blumm and Marienfeld

413 2013, USFWS 2015). While our results on L. tidestromii could be an isolated case, they suggest

414 that the extinction threat posed by climate change might be overlooked in temperate biomes.

415 Thus, we hope that our study serves as a model for other similar forecasting efforts using long-

416 term monitoring data.

\section{ACKNOWLEDGMENTS}

419 Funding for this research was provided by the NSF (DEB-0743731), the Alexander von

420 Humboldt foundation, and Washington University in St. Louis. We thank Valentin Ştefan for 
421 support with data processing. We thank Dr. Ben Becker at Point Reyes National Seashore for

422 lodging and extensive logistical support, and Lorraine Parsons at Point Reyes National Seashore

423 for long-term collaboration on the monitoring of this species, and sharing site-based knowledge.

424 We thank numerous students for assisting with field data collection, in particular Emily

425 Dangremond and Melissa Patten who worked at least three summers on this project. 


\section{REFERENCES}

429 Baldwin, B. G., D. H. Goldman, D. J. Keil, R. Patterson, T. J. Rosatti, and D. H. Wilken. 2012.

430 The Jepson Manual: Vascular Plants of California. University of California Press.

431 Barbier, E. B. 2015. Valuing the storm protection service of estuarine and coastal ecosystems.

432 Ecosystem Services 11:32-38.

433 Bates, D., M. Mächler, B. Bolker, and S. Walker. 2015. Fitting Linear Mixed-Effects Models

$434 \quad$ Using $\{$ lme4 $\}$. Journal of Statistical Software 67.

435 Beguería, S., and S. Vicente-Serrano. 2017. SPEI: Calculation of the Standardised Precipitation-

436 Evapotranspiration Index.

437 Blumm, M. C., and K. B. Marienfeld. 2013. Endangered Species Act Listings and Climate

438 Change: Avoiding the Elephant in the Room Symposium. Animal Law:277-310.

439 Burnham, K. P., and D. R. Anderson. 2002. Model Selection and Multimodel Inference: A

440 Practical Information-Theoretic Approach. Second edition. Springer-Verlag, New York.

441 Campbell, D. R. 2019. Early snowmelt projected to cause population decline in a subalpine

$442 \quad$ plant. Proceedings of the National Academy of Sciences 116:12901-12906.

443 Caswell, H. 2000. Prospective and Retrospective Perturbation Analyses: Their Roles in

444 Conservation Biology. Ecology 81:619-627.

445 Caswell, H. 2001. Matrix population models. Massachusetts: Sinauer Associates.

446 Cogoni, D., E. Sulis, G. Bacchetta, and G. Fenu. 2019. The unpredictable fate of the single 
CPC. (n.d.). https://origin.cpc.ncep.noaa.gov/products/analysis_monitoring/ensostuff/ONI_v5.php.

Daly, C., R. P. Neilson, and D. L. Phillips. 1994. A Statistical-Topographic Model for Mapping

Dangremond, E. M., E. A. Pardini, and T. M. Knight. 2010a. Apparent competition with an invasive plant hastens the extinction of an endangered lupine. Ecology 91:2261-2271.

Dangremond, E. M., E. A. Pardini, and T. M. Knight. 2010b. Apparent competition with an invasive plant hastens the extinction of an endangered lupine 91:11.

Doak, D. F., and W. F. Morris. 2010. Demographic compensation and tipping points in climateinduced range shifts. Nature 467:959-962.

467 Ehrlén, J., and W. F. Morris. 2015. Predicting changes in the distribution and abundance of species under environmental change. Ecology Letters 18:303-314. Systematics 40:677-697. 
472 Ellner, S. P., D. Z. Childs, and M. Rees. 2016. Data-driven Modelling of Structured Populations:

473 A Practical Guide to the Integral Projection Model. Springer International Publishing.

474 Evens, J. G. 2008. natural history of the Point Reyes Peninsula. University of California Press.

475 Feagin, R. A., D. J. Sherman, and W. E. Grant. 2005. Coastal erosion, global sea-level rise, and

476 the loss of sand dune plant habitats. Frontiers in Ecology and the Environment 3:359-

$477 \quad 364$.

478 Glenn, E. M., R. G. Anthony, and E. D. Forsman. 2010. Population trends in northern spotted owls: Associations with climate in the Pacific Northwest. Biological Conservation

Gneiting, T., and A. E. Raftery. 2007. Strictly Proper Scoring Rules, Prediction, and Estimation. Journal of the American Statistical Association 102:359-378. Ecology 91:2883-2897.

Iler, A. M., A. Compagnoni, D. W. Inouye, J. L. Williams, P. J. CaraDonna, A. Anderson, and T.

IPCC. 2014. Summary for policymakers. In: Climate Change 2014: Impacts, Adaptation, and 
494 Jenouvrier, S. 2013. Impacts of climate change on avian populations. Global Change Biology 19:2036-2057.

496 Jenouvrier, S., H. Caswell, C. Barbraud, M. Holland, J. Strœve, and H. Weimerskirch. 2009.

497 Demographic models and IPCC climate projections predict the decline of an emperor penguin population. Proceedings of the National Academy of Sciences 106:1844-1847.

499 Jonzén, N., T. Pople, J. Knape, and M. Sköld. 2010. Stochastic demography and population dynamics in the red kangaroo Macropus rufus. Journal of Animal Ecology 79:109-116.

501 Keenan, T., J. M. Serra, F. Lloret, M. Ninyerola, and S. Sabate. 2011. Predicting the future of forests in the Mediterranean under climate change, with niche- and process-based

504 Lande, R. 1993. Risks of Population Extinction from Demographic and Environmental Stochasticity and Random Catastrophes. The American Naturalist 142:911-927.

Luger, M. I. 1991. The economic value of the coastal zone:23.

509 Maron, J. L. 1998. Insect Herbivory Above- and Belowground: Individual and Joint Effects on Plant Fitness. Ecology 79:1281-1293.

511 Martínez, M. L., A. Intralawan, G. Vázquez, O. Pérez-Maqueo, P. Sutton, and R. Landgrave. 2007. The coasts of our world: Ecological, economic and social importance. Ecological Economics 63:254-272.

514 Morris, W. F., and D. F. Doak. 2005. How General Are the Determinants of the Stochastic 
Paniw, M., N. Maag, G. Cozzi, T. Clutton-Brock, and A. Ozgul. 2019. Life history responses of meerkats to seasonal changes in extreme environments. Science 363:631-635. 10:e0119567.

521 Pereira, H. M., P. W. Leadley, V. Proença, R. Alkemade, J. P. W. Scharlemann, J. F. Fernandez-

526 Pisanu, S., E. Farris, R. Filigheddu, and M. B. García. 2012. Demographic effects of large, introduced herbivores on a long-lived endemic plant. Plant Ecology 213:1543-1553.

528 Proosdij, A. S. J. van, M. S. M. Sosef, J. J. Wieringa, and N. Raes. 2016. Minimum required number of specimen records to develop accurate species distribution models. Ecography 39:542-552.

531 Sæther, B.-E., J. Tufto, S. Engen, K. Jerstad, O. W. Røstad, and J. E. Skåtan. 2000. Population Dynamical Consequences of Climate Change for a Small Temperate Songbird. Science

534 Schurr, F. M., J. Pagel, J. S. Cabral, J. Groeneveld, O. Bykova, R. B. O’Hara, F. Hartig, W. D. 2012. How to understand species' niches and range dynamics: a demographic research 
538 Svenning, J.-C., and F. Skov. 2004. Limited filling of the potential range in European tree species. Ecology Letters 7:565-573.

Teller, B. J., P. B. Adler, C. B. Edwards, G. Hooker, and S. P. Ellner. 2016. Linking demography with drivers: climate and competition. Methods in Ecology and Evolution 7:171-183.

542 Tenhumberg, B., E. E. Crone, S. Ramula, and A. J. Tyre. 2018. Time-lagged effects of weather on plant demography: drought and Astragalus scaphoides. Ecology 99:915-925.

544 Tews, J., and F. Jeltsch. 2004. Modelling the impact of climate change on woody plant population dynamics in South African savanna. BMC Ecology 4:17.

546 USFWS. 1998. Seven coastal plants and the Myrtle's silverspot butterfl y recovery plan.

547 USFWS, Portland, Oregon, USA.

548 USFWS. 2009. Lupinus tidestromii (Clover lupine) 5-Year Review: Summary and Evaluation. 549 Sacramento Fish and Wildlife Office, Sacramento, California, USA.

550 USFWS. 2015. Polar Bear (Ursus maritimus) Conservation Management Plan, Draft. U.S. Fish and Wildlife, Region 7, Anchorage, Alaska.

552 USGCRP. 2018. Fourth National Climate Assessment. U.S. Global Change Research Program, $553 \quad$ Washington, DC, USA.

554 Vicente-Serrano, S. M., S. Beguería, and J. I. López-Moreno. 2009. A Multiscalar Drought Index 555 Sensitive to Global Warming: The Standardized Precipitation Evapotranspiration Index. $556 \quad$ Journal of Climate 23:1696-1718.

557 Vose, R. S., D. R. Easterling, K. E. Kunkel, A. N. LeGrande, and M. F. Wehner. 2017. Temperature Changes in the United States. Climate Science Special Report: Fourth National Climate Assessment, Volume I. U.S. Global Change Research Program. 
560 Wang, T., A. Hamann, D. Spittlehouse, and C. Carroll. 2016. Locally Downscaled and Spatially

561 Customizable Climate Data for Historical and Future Periods for North America. PLOS

$562 \quad$ ONE 11:e0156720.

563 Wang, T., A. Hamann, D. Spittlehouse, and C. Carroll. (n.d.). ClimateNA_MAP -- An

564 Interactive Plantform for Visualization and Data Access. 
567 Table 1. Cross-validation results based on log-likelihood. The models with higher support

568 appear first, those with the least support are last. Model "null" does not contain a climatic

569 predictor. We compare models with four annual climatic anomalies: temperature (tmp),

570 precipitation (ppt), Oceanic Niño Index (oni), and the standardized precipitation

571 evapotranspiration index (spei). Moreover, we compare models with climatic predictors referred

572 to two years: the year of the demographic census $(t)$ and that preceding it $(t-1)$.

\begin{tabular}{|c|c|c|c|c|c|c|c|}
\hline \multicolumn{2}{|c|}{ Survival } & \multicolumn{2}{|c|}{ Growth } & \multicolumn{2}{|c|}{ Flowering } & \multicolumn{2}{|c|}{ Racemes } \\
\hline Mode & log_lik_sum & Mode & log_lik_sum & Mode & g_lik_sun & Model & g_lik_sum \\
\hline $\mathrm{tmp}_{\mathrm{t}}$ & 8320.713 & null & $9643.2 \overline{7} 1$ & $\mathrm{tmp}_{\mathrm{t}}$ & 4860.26 & $\mathrm{tmp}_{\mathrm{t}}$ & 20538.58 \\
\hline null & 8339.689 & $\operatorname{ppt}_{\mathrm{t}-1}$ & 9683.304 & null & 5594.39 & null & 20863.18 \\
\hline $\operatorname{spei}_{t-1}$ & 8378.673 & spei $_{t}$ & 9690.057 & oni $_{t}$ & 5794.02 & $\mathrm{ppt}_{\mathrm{t}}$ & 20886.95 \\
\hline oni $_{t}$ & 8382.177 & $\mathrm{ppt}_{\mathrm{t}}$ & 9696.37 & $\mathrm{tmp}_{\mathrm{t}-1}$ & 5804.95 & spei_to & 21036.85 \\
\hline $\mathrm{tmp}_{\mathrm{t}-1}$ & 8385.776 & spei $_{\mathrm{t}-1}$ & 9697.36 & $\operatorname{spei}_{t-1}$ & 5874.91 & $\mathrm{tmp}_{\mathrm{t}-1}$ & 21236.65 \\
\hline $\mathrm{ppt}_{\mathrm{t}}$ & 8408.783 & oni $_{t-1}$ & 9697.919 & $\mathrm{ppt}_{\mathrm{t}-1}$ & 5876.70 & oni $_{t}$ & 21281.96 \\
\hline onit-1 & 8439.169 & $\operatorname{tmp}_{\mathrm{t}-1}$ & 9700.742 & onit-1 & 5882.69 & $\mathrm{ppt}_{\mathrm{t}-1}$ & 21292.39 \\
\hline speit $_{t}$ & 8442.731 & oni $_{t}$ & 9730.185 & speit $_{t}$ & 5888.28 & speit-1 & 21326.18 \\
\hline $\mathrm{ppt}_{\mathrm{t}-1}$ & 8494.641 & $\mathrm{tmp}_{\mathrm{t}}$ & 9808.604 & $\mathrm{ppt}_{\mathrm{t}}$ & 5890.52 & oni $\mathrm{t}_{\mathrm{t}-1}$ & 21336.45 \\
\hline
\end{tabular}




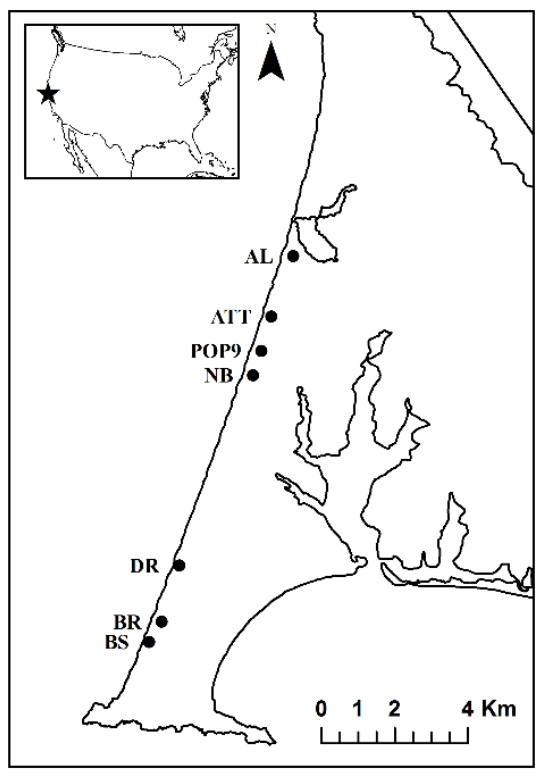

575 Figure 1. Map of the seven study populations of L. tidestromii at Point Reyes National Seashore,

576 Marin County, California, USA. The entire range of this species includes two additional clusters

577 of populations located in Sonoma and Monterey county. 


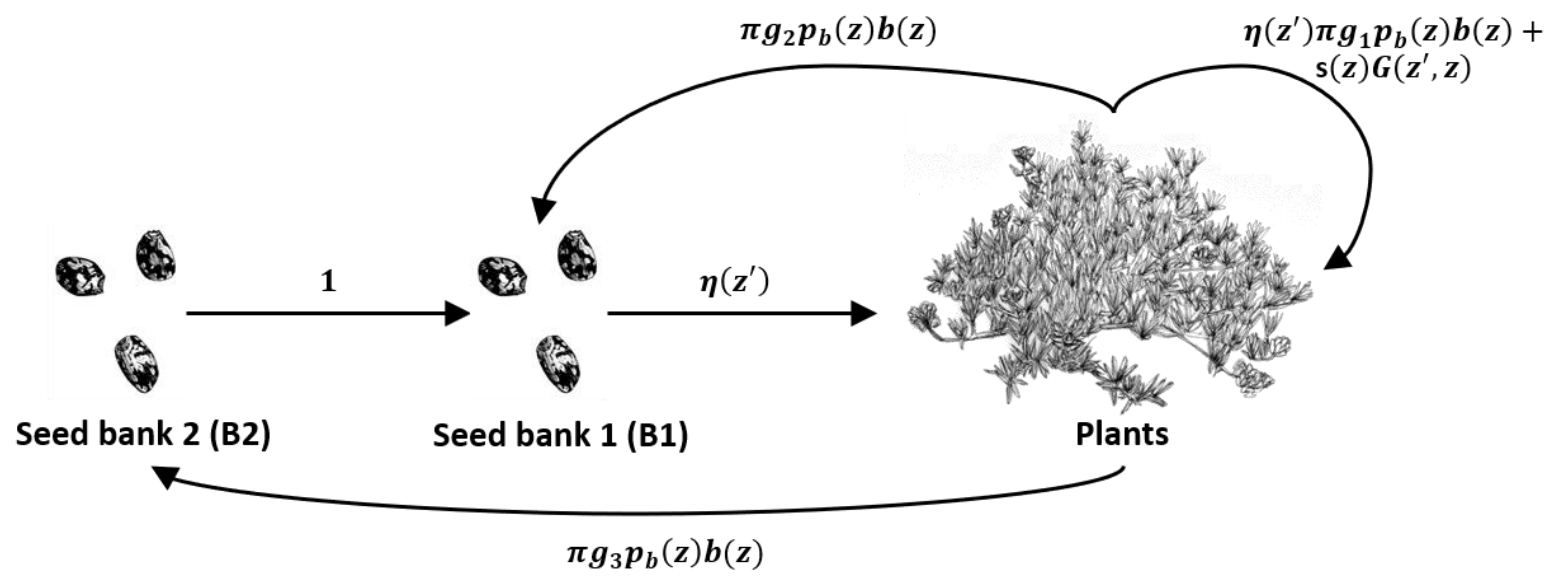

580 Figure 2. Life cycle model for L. tidestromii. This life cycle refers to the IPM described in

581 Appendix S6 (Eq. 7-9). The IPM separates the population in three discrete stages: continuously

582 sized plants (plants), seeds that germinate after one winter $(B 1)$, and seeds that germinate after

583 two winters (B2). These stages are modeled, respectively, by equation 9,7 , and 8 in Appendix

584 S6. To minimize the use of space, in this figure $\pi$ corresponds to $(1-a)(1-c) \iota \kappa(1-\delta)$ in

585 Equations 7-9. 

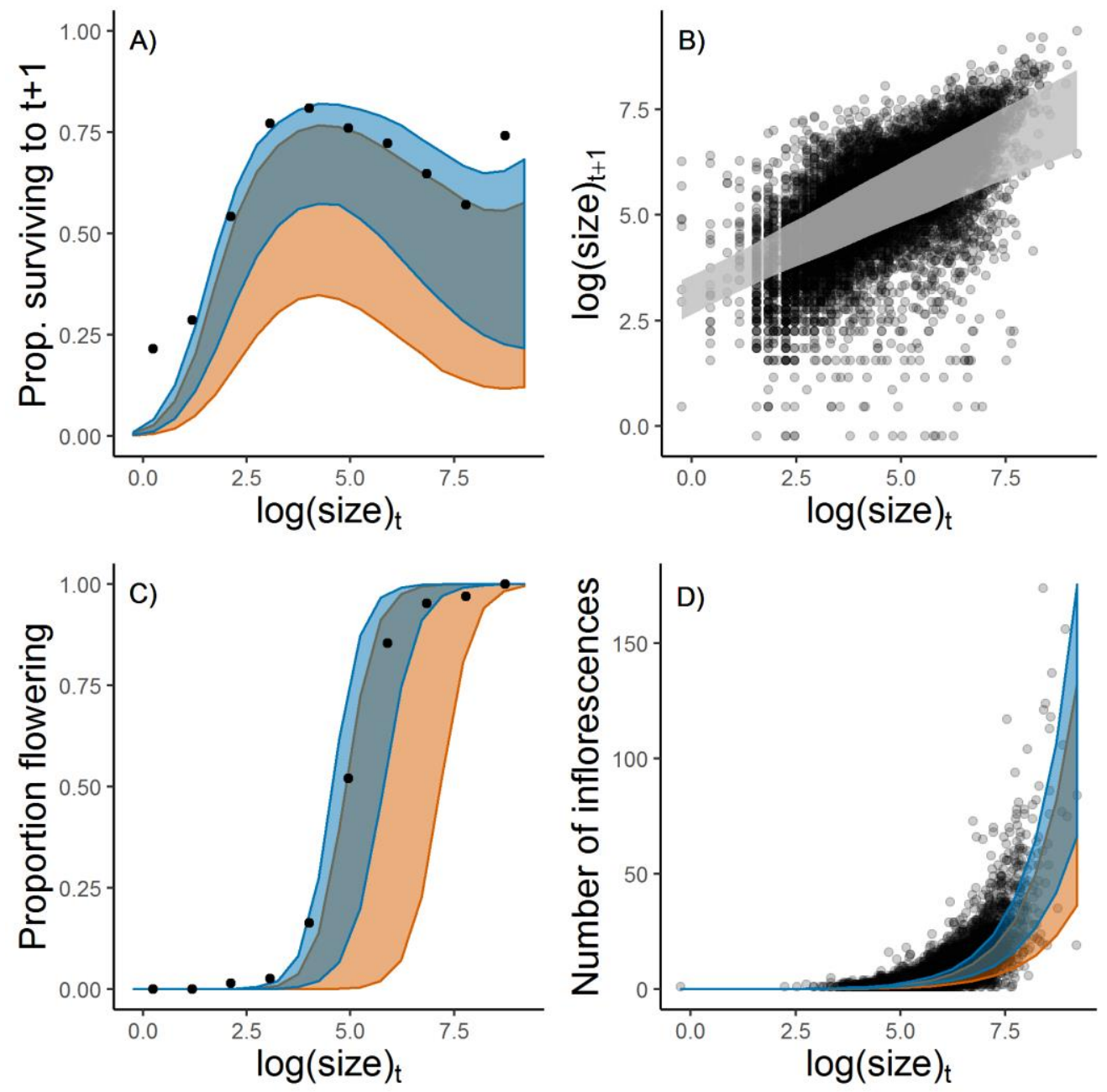

588 Figure 3. The effect of plant size and mean annual temperature (when relevant) on survival (A),

589 growth (B), the probability of flowering (C), and the production of racemes (D). The dots in the

590 plots showing survival (A) and probability of flowering (C) represent the average proportion of

591 individuals surviving and flowering, respectively, within 10 equally spaced intervals of

592 individual log sizes. Shaded areas show the 95\% confidence intervals of the mean model

593 predictions. For the three climate-dependent vital rates, we show credible intervals of vital rates

594 responding to the average yearly temperature observed between 1990 and $2018\left(12^{\circ}\right.$ Celsius, in

595 blue), and the highest average yearly temperature observed during the same period $\left(13^{\circ}\right.$ Celsius,

596 in orange). 

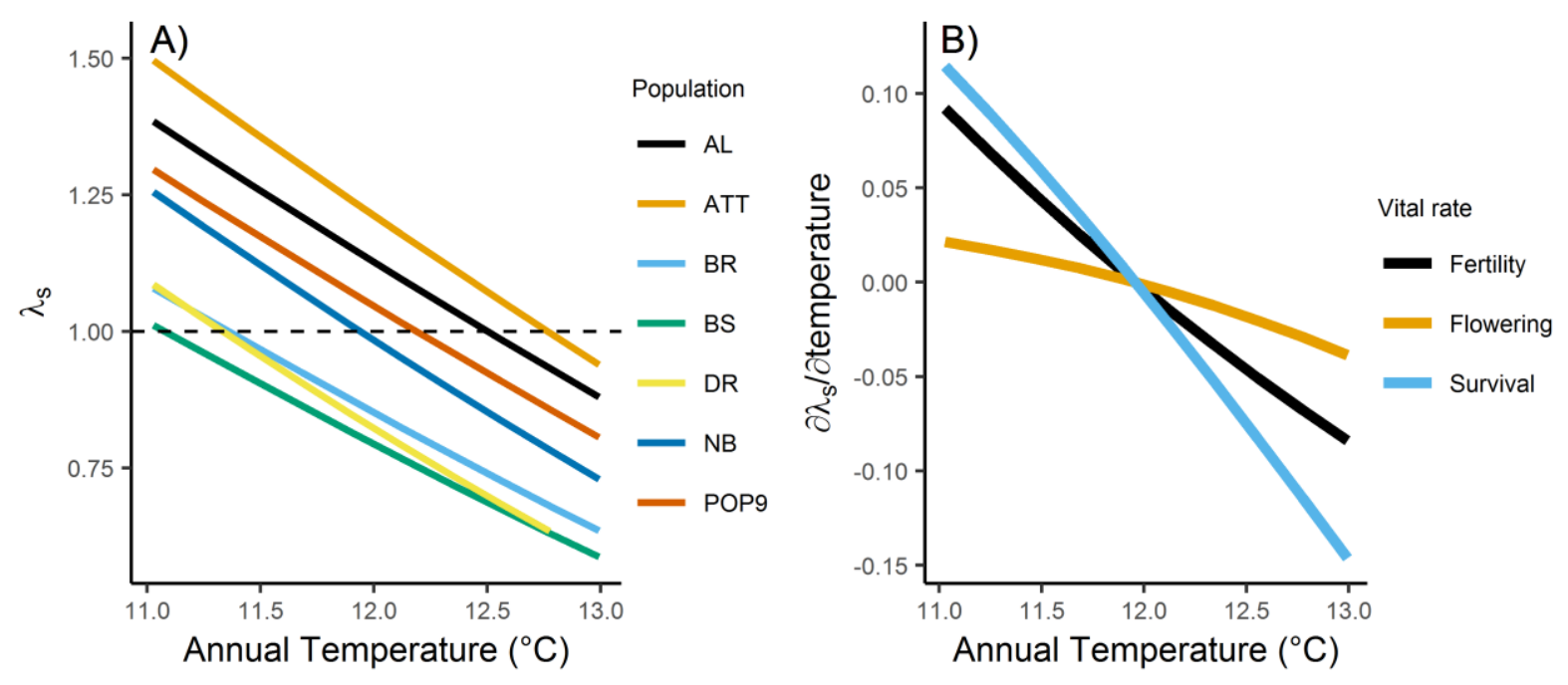

598 Figure 4. Long-term stochastic population growth rate $\left(\lambda_{s}\right)$ as a function of mean annual

599 temperature for each of the seven L. tidestromii populations (A), and the partial effect of each

600 climate-dependent vital rate on the $\lambda_{\mathrm{s}}(\mathrm{B})$. The average yearly temperature observed between

6011990 and 2018 was $12^{\circ}$ Celsius; the average temperature during the study period was $11.5^{\circ}$

602 Celsius. 


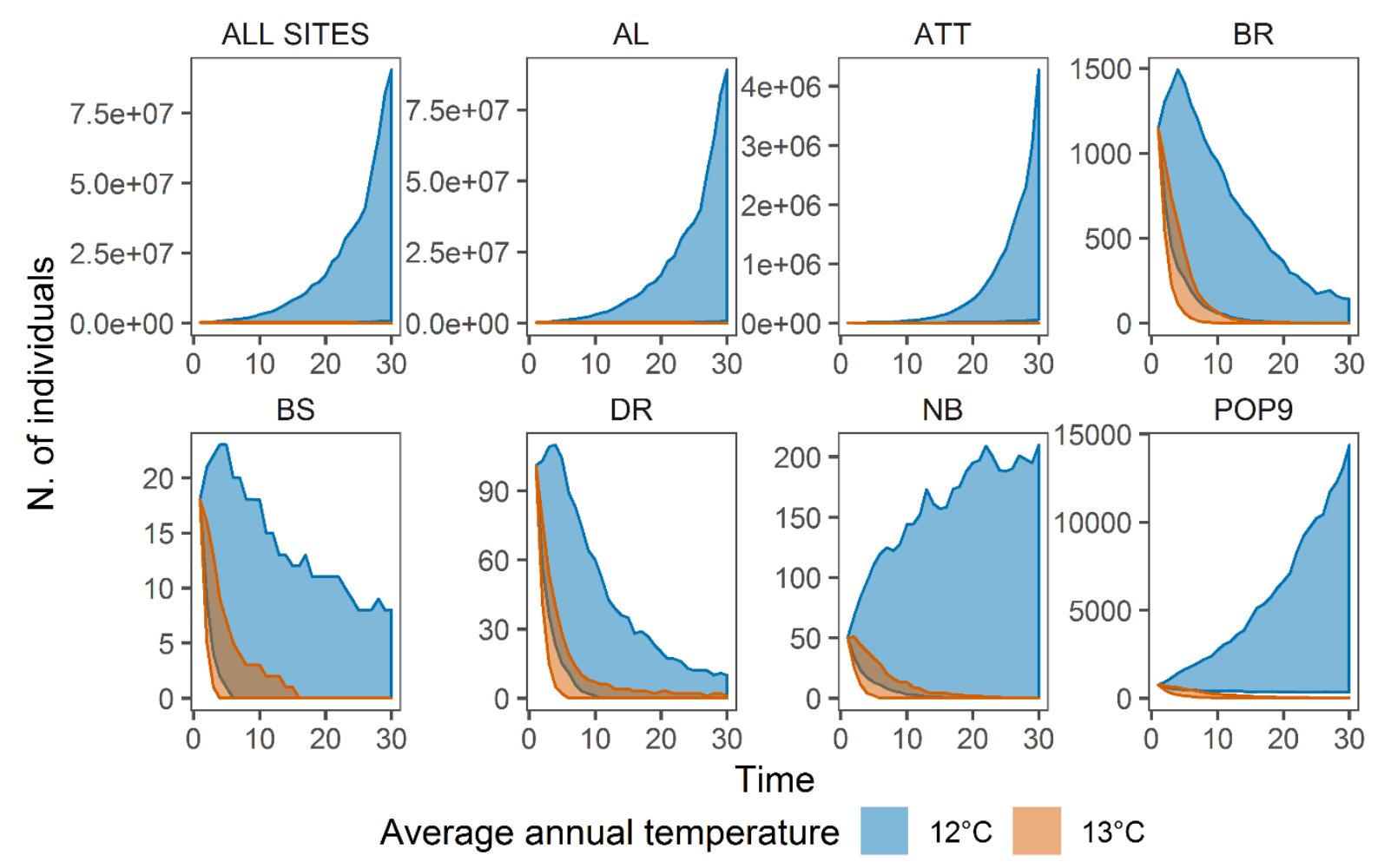

605 Figure 5. Projected population sizes of L. tidestromii assuming historical $\left(12^{\circ}\right.$ Celsius $)$ and

606 future average annual temperatures $\left(13^{\circ}\right.$ Celsius $)$. Polygons show the lower $2.5^{\text {th }}$ and upper $97.5^{\text {th }}$

607 percentile of 1000 separate projections. The upper left panel shows the population sizes of all

608 sites at Point Reyes National Seashore; the remaining panels show the population sizes at each

609 one of the seven sites separately. Each simulation was initiated using the population sizes

610 observed in 2018.

611 


\section{APPENDICES}

614 Appendix S1: Plant size estimation

615 We estimated plant size in terms of surface area covered by each individual. However, our way

616 to estimate this are changed before and after 2008. Before 2008 we quantified size counting the

617 number of branches on a plant. After 2008, we quantified the area of each individual

618 approximating it using as an ellipse (e.g. Morris and Doak 2005). The major axis of this ellipse

619 was the longest segment covered by each individual, the minor axis the width perpendicular to

620 the major axis. For data before 2008, we inferred the area of the ellipse by developing a

621 regression that used a sample of plants for which we counted branches and measured major and

622 minor axis length. In total, this regression contained 234 plants (82 measured in 2008, 152 in

623 2018). We predicted area as a quadratic function of the number of branches (Fig. S1).

\section{REFERENCES}

626 Morris, W.F. \& Doak, D.F. (2005). How General Are the Determinants of the Stochastic Population 


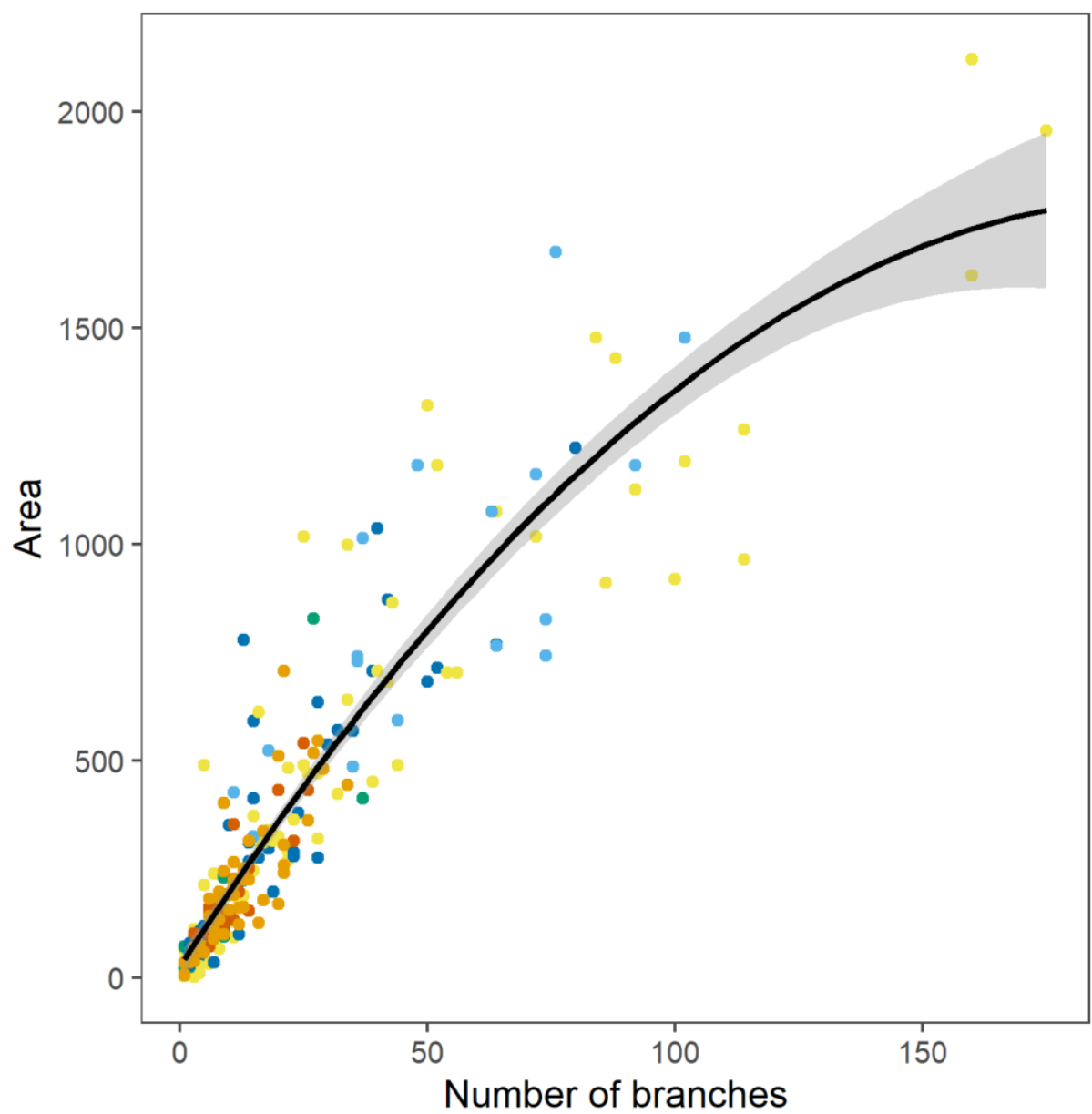

\section{POPULATION}

- $\mathrm{ATT}(8)$

- $\operatorname{BR}(6)$

- $\operatorname{BS}(7)$

- DR (3)

- NB (2)

- $\operatorname{POP9}(9)$

630 Figure S1. Relationship between the number of branches counted on L. tidestromii plants, and their area. The black line represents the mean model prediction of the quadratic linear model that describes the relationship between area and the number of branches. The grey area represents the $95 \%$ confidence interval of the mean model prediction. The color of dots refers to data from six separate populations. 
637

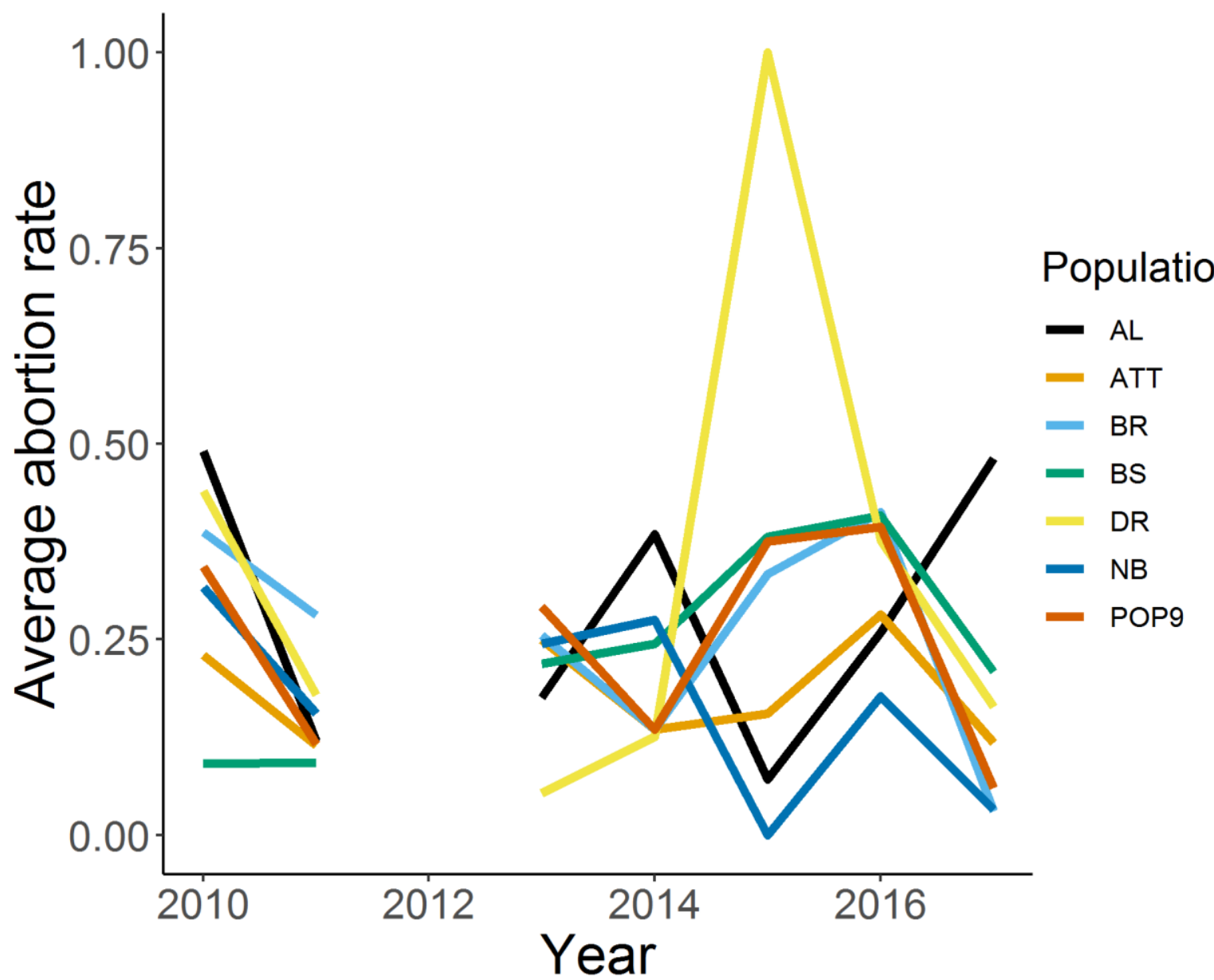

639

Figure S2. Average abortion rate of inflorescences by year and population. 


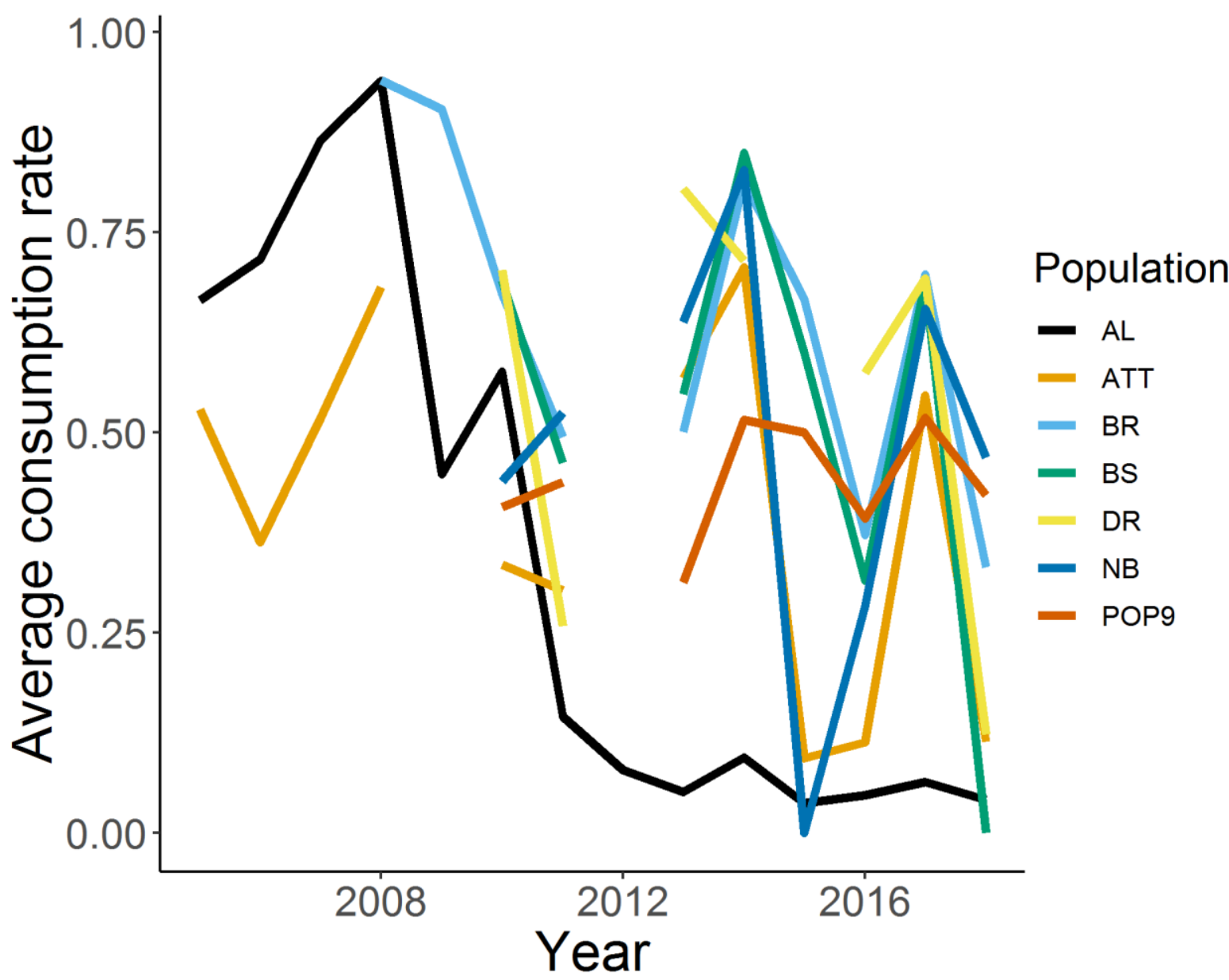

642

643

Figure S3. Average consumption rate by year and population. 
bioRxiv preprint doi: https://doi.org/10.1101/2020.08.02.233288; this version posted October 27, 2020. The copyright holder for this preprint (which was not certified by peer review) is the author/funder, who has granted bioRxiv a license to display the preprint in perpetuity. It is made available under aCC-BY-NC-ND 4.0 International license.

644 645

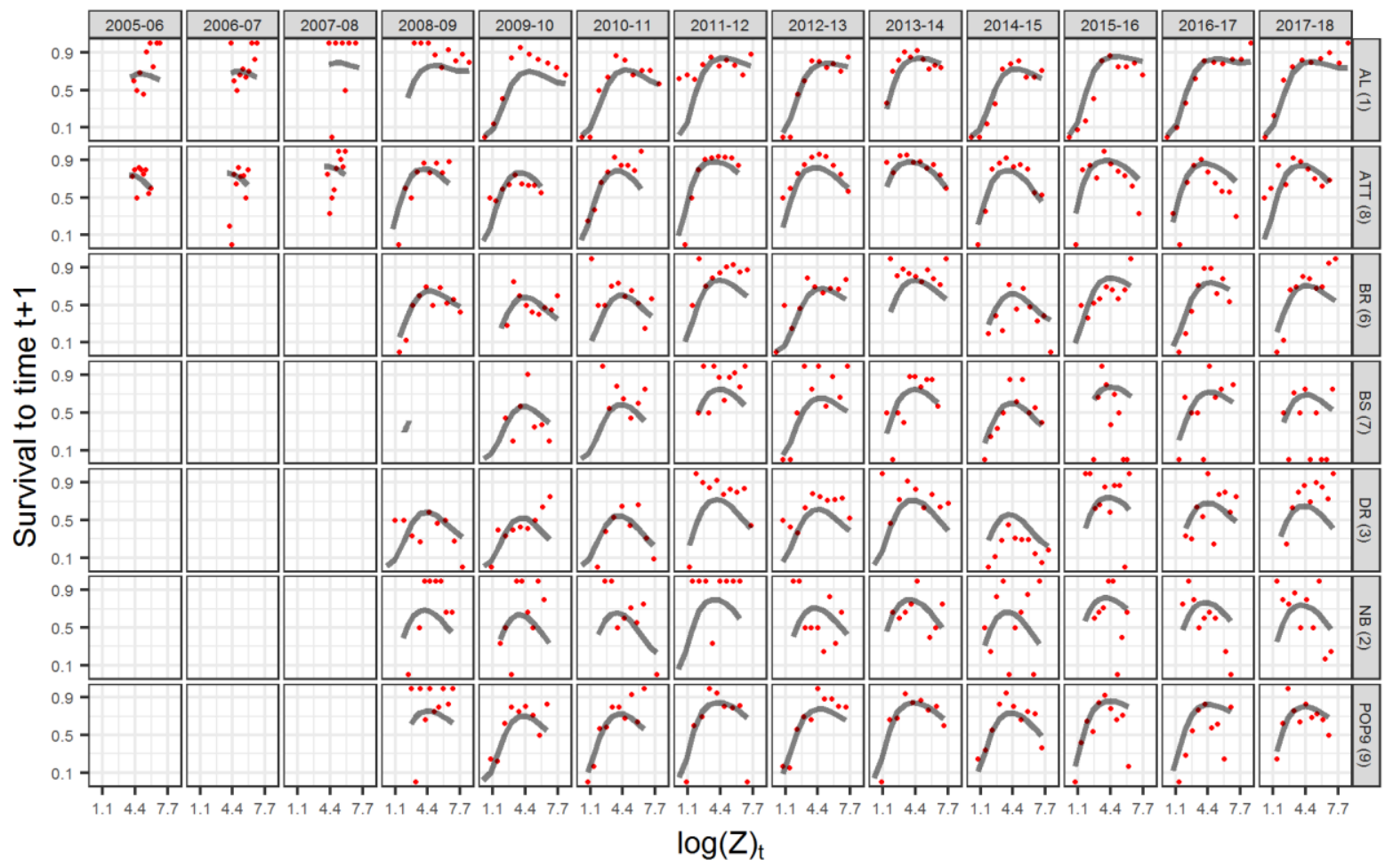

Figure S4. Survival to time $t+1$ of individuals of size $\log (\mathrm{Z})$ at time $t$, by transition year (columns) and population (rows). Red dots show the observed proportion of surviving individuals in ten equally spaced size $\log (\mathrm{Z})$ intervals at time $t$. Grey lines show the average sizedependent survival probability predicted by the generalized linear mixed model. 
bioRxiv preprint doi: https://doi.org/10.1101/2020.08 .02 233288; this version posted October 27,2020. The copyright holder for this preprint (which was not certified by peer review) is the author/funder, who has granted bioRxiv a license to display the preprint in perpetuity. It is made available under aCC-BY-NC-ND 4.0 International license.

650 651

652

653

654

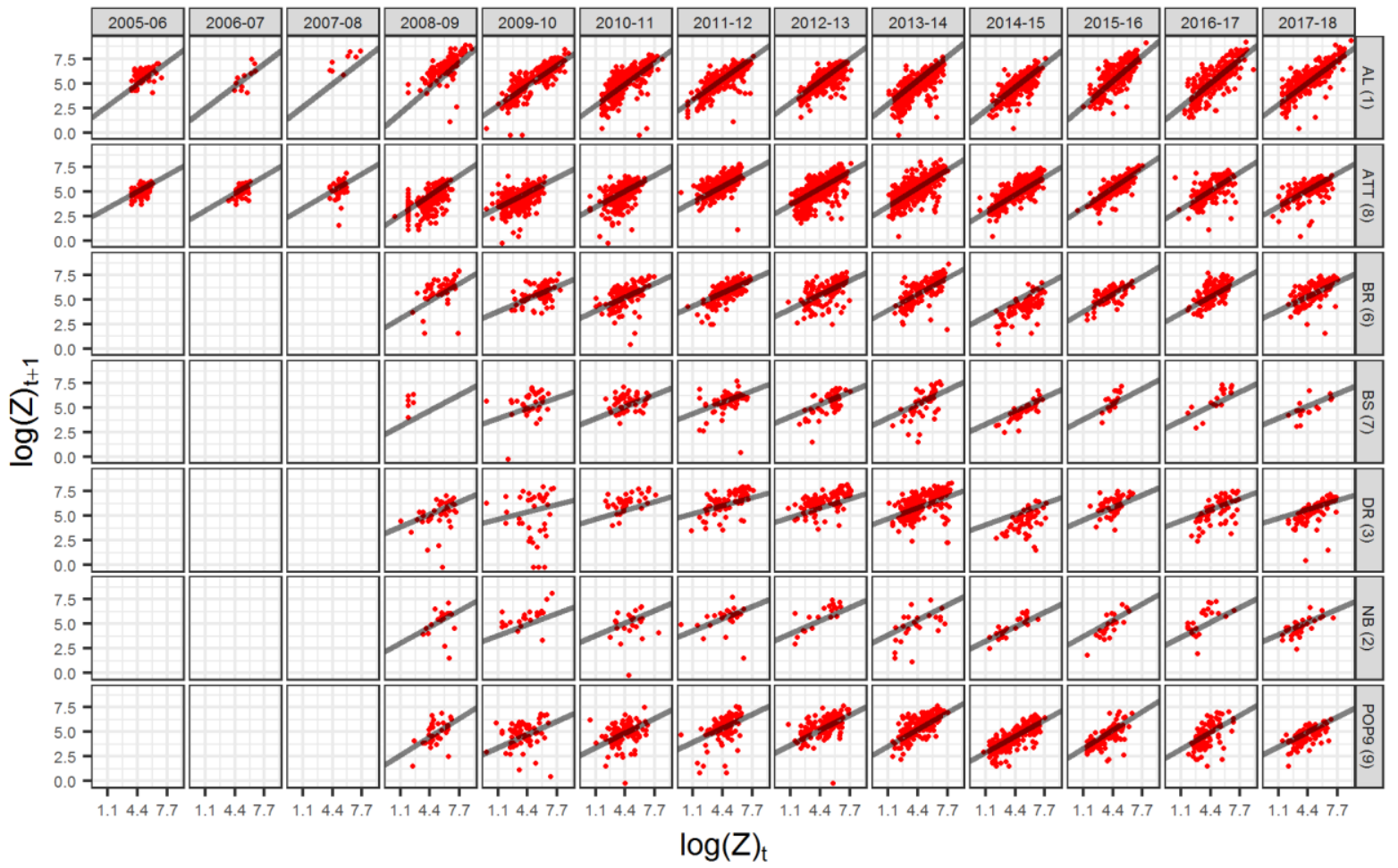

Figure S5. Individual $\log$ size $(Z)$ at time $t+1$ as a function of individual log size $(Z)$ at time $t$, by transition year (columns) and population (rows). Red dots show individual data points, and grey lines show the prediction of the linear mixed model. 
bioRxiv preprint doi: https://doi.org/10.1101/2020.08.02 233288. this version posted October 27 2020. The copyright holder for this preprint (which was not certified by peer review) is the author/funder, who has granted bioRxiv a license to display the preprint in perpetuity. It is made available under aCC-BY-NC-ND 4.0 International license.

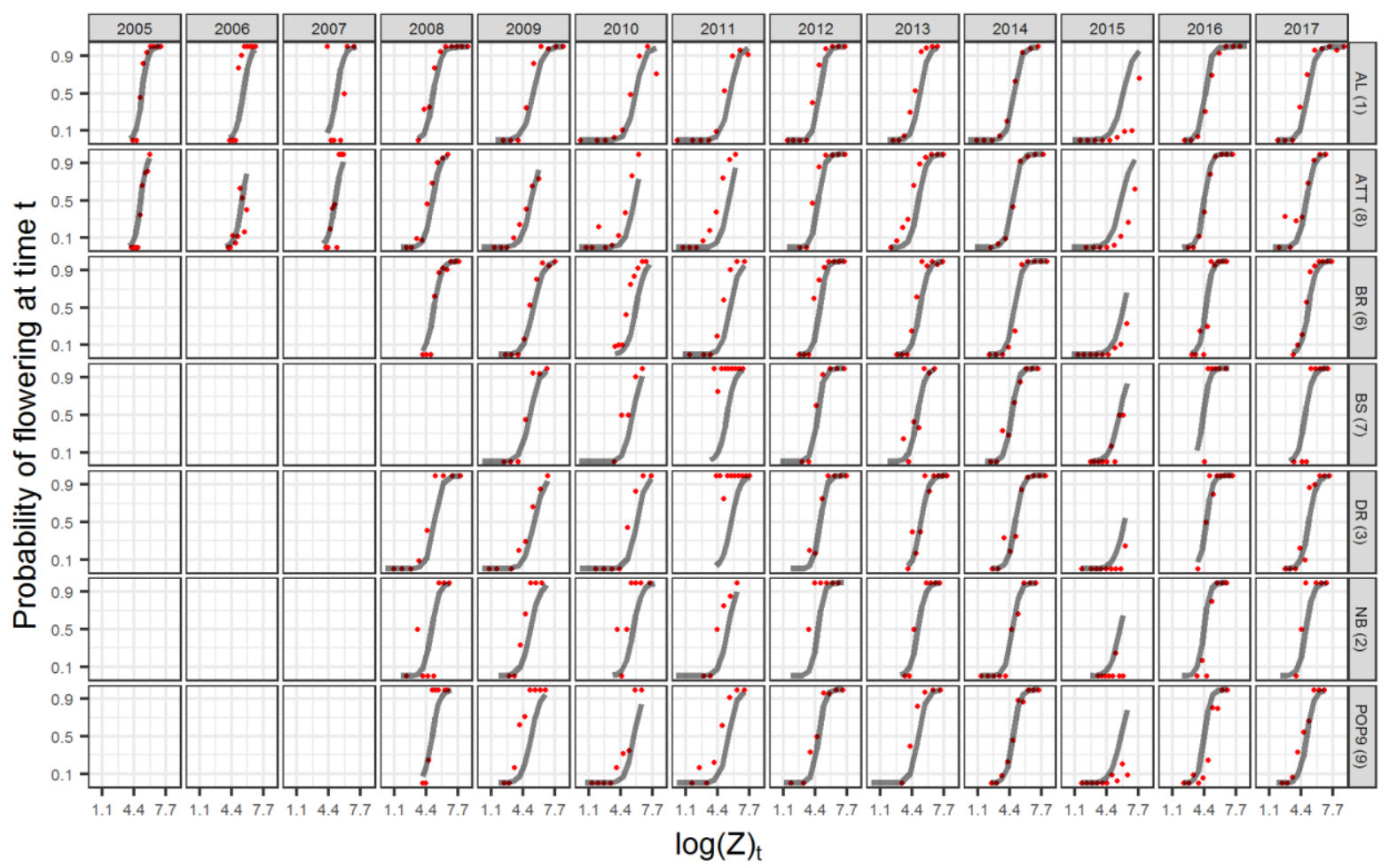

655
Figure S6. Flowering probability at time $t$ based on the log size of individuals (Z) at time $t$, by year (columns) and population (rows). Red dots show the observed proportion of flowering individuals in ten equally spaced intervals of log sizes at time $t$. Grey lines show the average size-dependent flowering probability predicted by the generalized linear mixed model. 
bioRxiv preprint doi: https://doi.org/10.1101/2020.08.02 233288. this version posted October 27 2020. The copyright holder for this preprint (which was not certified by peer review) is the author/funder, who has granted bioRxiv a license to display the preprint in perpetuity. It is made available under aCC-BY-NC-ND 4.0 International license.

661

662

663

664

665

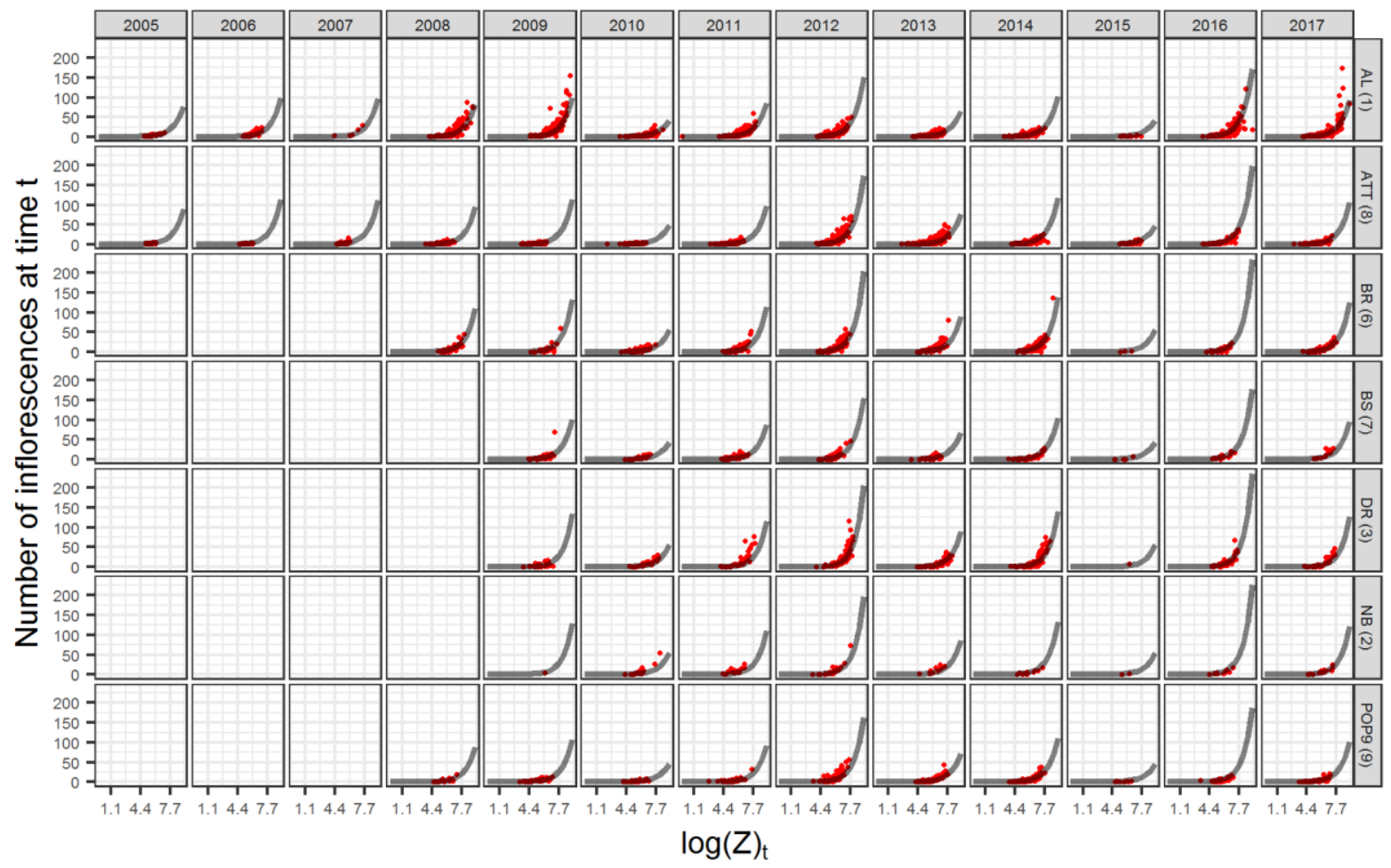

Figure S7. Production of inflorescences by reproductive individuals at time $t$ as a function of individual $\log$ size $(Z)$ at time t, by year (columns) and population (rows). Red dots show individual data points, and grey lines show the predictions of the generalized linear mixed model. 


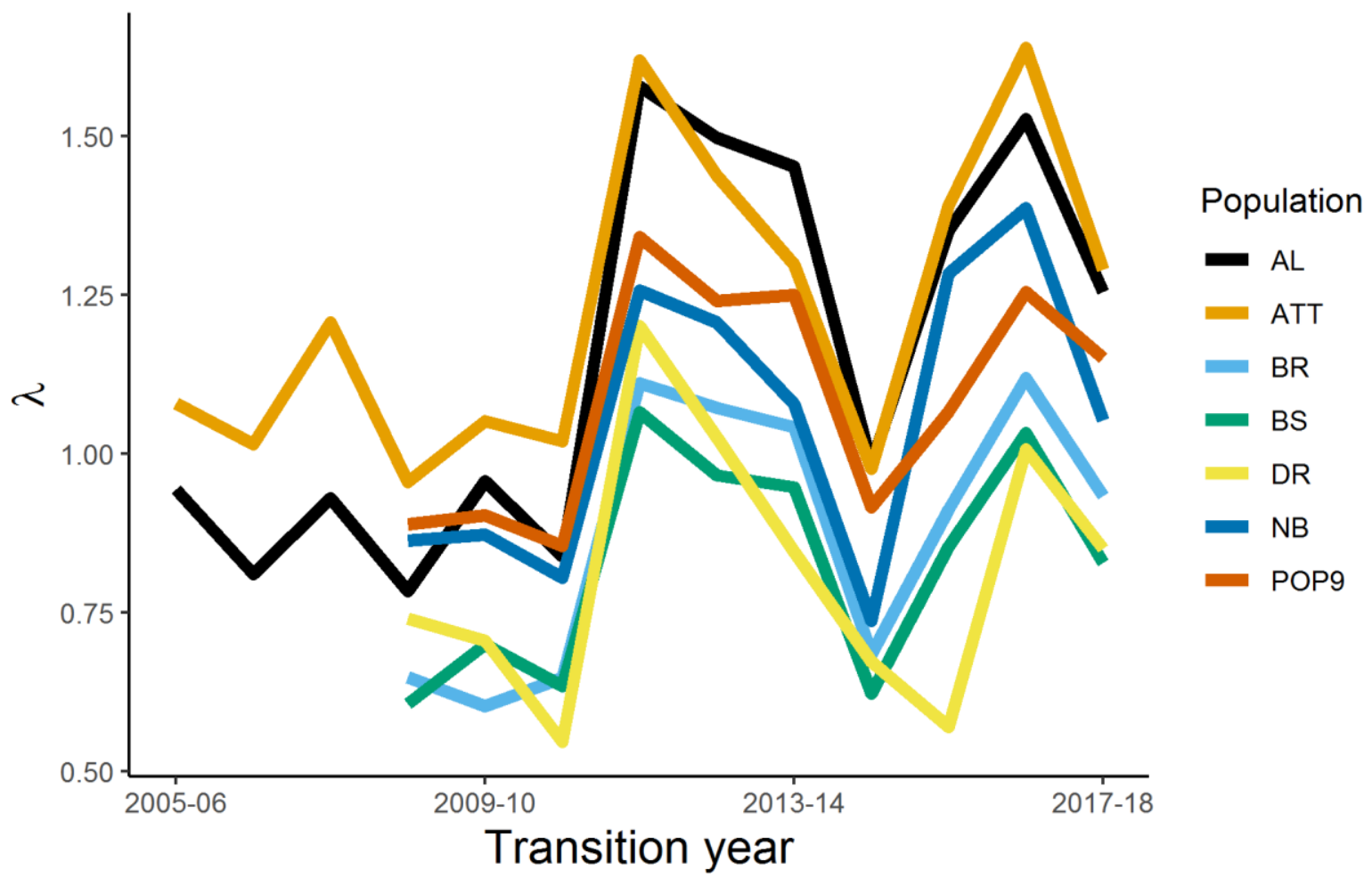

667 Figure S8. Asymptotic population growth rates $(\lambda)$ based on transition year and population. $\lambda$ are 668 calculated using year- and population- specific integral projection models. $\lambda$ values prior to the 2008-2009 transition are available for two sites only (AL and ATT). 


\section{Appendix S3: Calculation of the germination adjustment factor}

672

673

674

675

676

677

678

679

680

681

682

683

684

685

686

687

688

689

690

691

692

693

694

695

696

697

698

699

700

We estimated a germination adjustment factor, $\delta$, by combining information on germination trials, on seed production, and on the number of new seedlings. We used data from "known population counts", which refers to the populations and transition years for which we have counted the total number of individuals and seedlings. First, we estimated the expected number of seeds produced at each population, $p$, and year, $t$ (estimated seed $s_{p t}$ ). To estimate the number of seeds, we used year- and population-specific consumption and abortion, and constant values of fruits per inflorescence and seeds per fruit data. We then used the ratio of observed seedlings $\mathrm{pt}_{+1}$ to the estimated seeds $\mathrm{pt}_{\mathrm{pt}}$ to calculate the recruitment adjustment factor $\delta$ :

$$
\frac{\text { observed seedlings }_{p t+1}}{\text { estimated seeds }}=g_{1}\left(1-\delta_{p}\right)
$$

Rearranging,

$$
\delta_{p}=\frac{g_{1}-\left(\frac{\text { observed seedling } s_{p t+1}}{\text { estimated seeds }}\right)}{g_{1}}
$$

Where $g_{1}$ is the proportion of seeds germinating in the first year (after one winter) in the germination experiment. In our population models, we apply $\delta_{p}$ to $g_{2}$ and $g_{3}$ because calculating $\delta_{p}$ using $g_{l}$ provides a conservative estimate of unobserved seed and seedling mortality. Our $\delta_{p}$ is conservative because the observed seedlings at $t+1$ emerge from dispersed seeds $\left(g_{l}\right)$ and from the seed bank $\left(g_{2}, g_{3}\right)$. We modified germination rates $g_{1}, g_{2}$, and $g_{3}$ used in the IPM using $\delta_{p}$ as:

$$
g_{t}\left(1-\delta_{p}\right)
$$

We could only calculate $\delta_{p}$ for the five populations with known population counts. For population BR, we applied the mean of $\delta_{p}$ from BS and DR; for AL, we applied the mean of $\delta_{p}$ from ATT and Pop9. We used these estimates due to the geographic proximity of BR and AL to these smaller populations for which $\delta$ could be quantified. We could only calculate $\delta_{p}$ for the five populations with known population counts. For population BR, we applied the mean of $\delta_{p}$ from BS and DR; for AL, we applied the mean of $\delta_{p}$ from ATT and Pop9. We used these estimates due to the geographic proximity of BR and AL to these smaller populations for which $\delta$ could be quantified. 


\section{Appendix S4: Individual based model}

702 Our individual based model simulated each probabilistic event in the life cycle of L. tidestromii

703 (Appendix S1: Fig. S3) using an appropriate statistical distribution. Our probabilistic events were

704 linked to survival, growth, probability of flowering, production of inflorescences, the abortion of

705 inflorescences, the consumption of inflorescences, and the germination of seeds. Starting from

706 the production of flowers, each individual flowered based on a Bernoulli process depending on

707 its individual size, so that:

$$
\text { Flower Bernoulli }\left(p_{b}\left(z ; \beta_{c}\right)\right)
$$

Where Flower is either a 0 , if an individual failed to flower, or 1 , if an individual flowered. $p_{b}\left(z ; \beta_{c}\right)$ shows that the probability of reproduction depends on individual size, $z$, and on the climate anomaly. If an individual reproduces, its production of inflorescences depends on a negative binomial distribution, so that

$$
\text { Racemes } N \sim \operatorname{Poisson}\left(b\left(z ; \beta_{c}\right), \theta\right)
$$

Which is also a size- and climate- dependent process. The number of inflorescences would decrease because of abortion following a binomial process

$$
\text { RacemesN Binomial(RacemesN, }(1-a) \text { ) }
$$

717 where 1- $a$ is the probability of an inflorescence not aborting. The remaining inflorescences could 718 still be consumed by predators,

$$
\text { RacemesN Binomial(Racemes } N,(1-c))
$$

where 1-c is the probability of not being consumed (the probability of experiencing pre-dispersal predation). The seeds produced by the surviving inflorescences on each individual could then

722 germinate based on a binomial process, so that:

$$
\text { Seedling } N \sim \text { Binomial (seeds, } g_{t}(1-\delta) \text { ) }
$$

724 Where SeedlingN is the number of seedlings emerging in each population, and $g_{t}$ is one of the germination rates associated with seeds that germinate in the year of the transition $\left(\mathrm{g}_{0}\right)$, the year after $\left(\mathrm{g}_{1}\right)$, and two years after $\left(\mathrm{g}_{2}\right)$. Finally, individuals could survive based on a size- and climate-dependent Bernoulli process

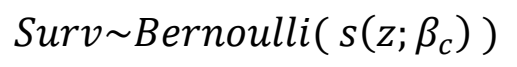

and, in case they survived, they could grow based on a normal process:

$$
z^{\prime} \sim \operatorname{Normal}\left(G\left(z^{\prime}, z\right), \sigma\right) \text {. }
$$


Appendix S5: Climatic anomalies figure

733
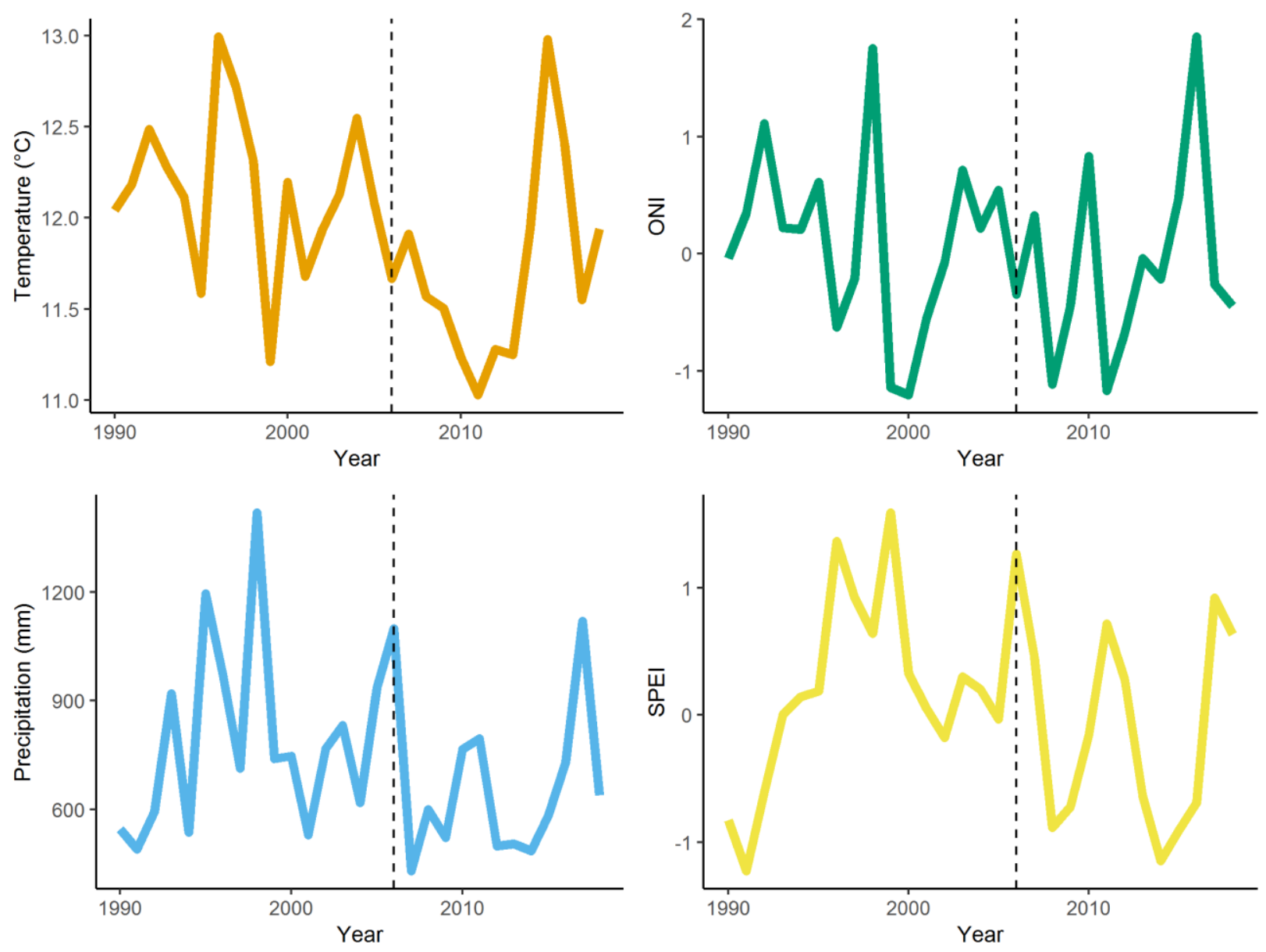

735

736

737

Figure S9. Annual climate values of temperature, precipitation, Oceanic Niño Index (ONI), and standardized aridity index (SPEI) between 1990 and 2018. The dashed lines denote the beginning 738 of L. tidestromii demographic censuses. 


\section{Appendix S6: Elasticity analysis}

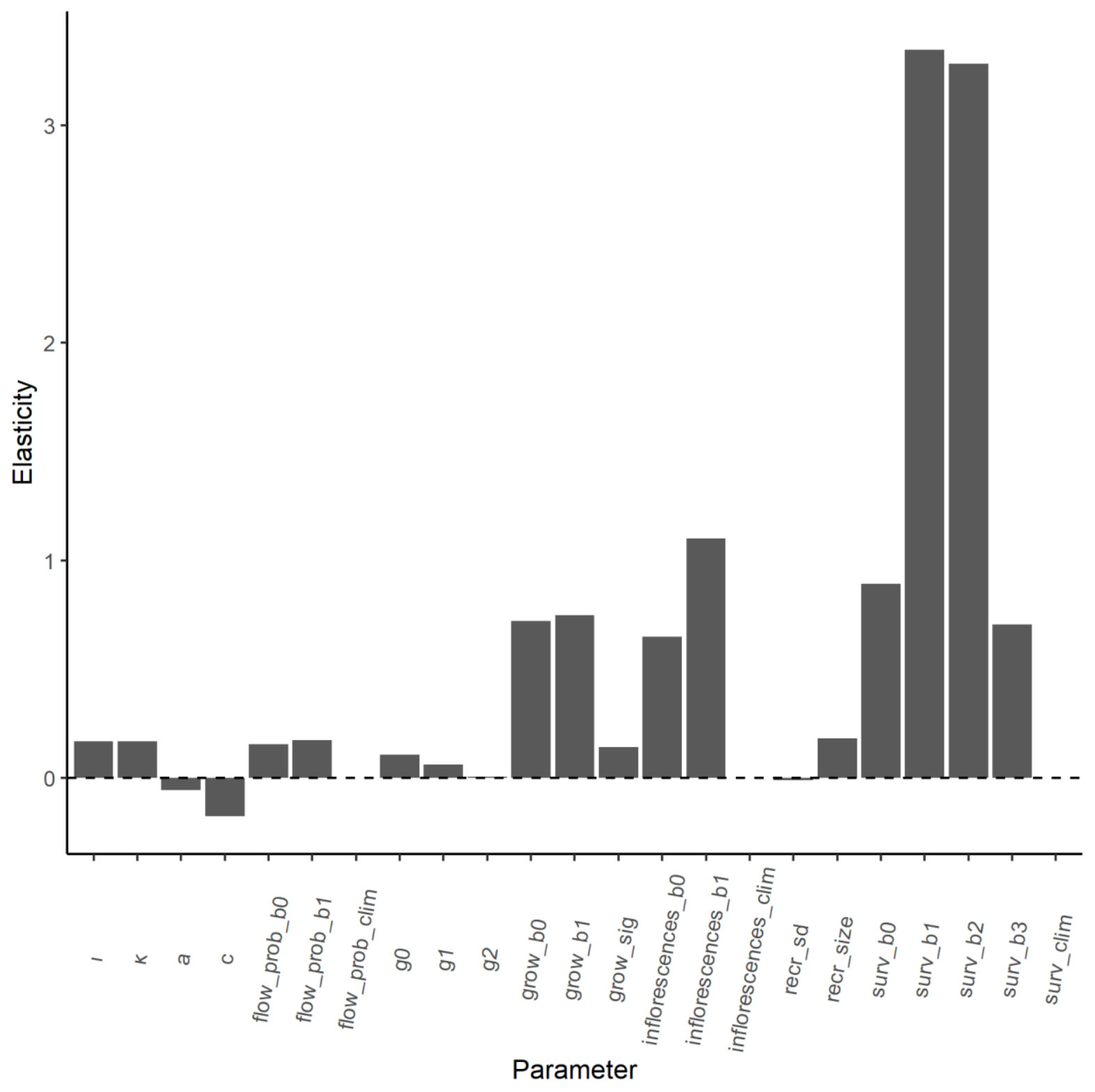

Figure S10. Elasticity of asymptotic population growth rate $(\lambda)$ to the parameters of the IPM. Parameters refer to the average values across years and populations. The elasticity is a proportional sensitivity, meaning that it quantifies by what percentage $\lambda$ will change after a percent change in each parameter. Thus, elasticity facilitates the comparison among parameters. The parameter names for size-dependent processes show the effect of annual temperature anomaly (_clim), the intercept of linear models (_b0), and the linear (_b1), quadratic (_b2), and cubic (_b3) effects of size. Parameters "recr_size" and "recr_sd" refers to the mean size and standard deviation of recruits. The remaining parameter names are identical to those in equations 7-9. Note that, unlike the elasticity of the IPM kernel elements, the elasticity of lower level parameters can exceed one. 